\title{
RHEOLOGY OF WAXY CRUDE OILS IN RELATION TO RESTART OF GELLED PIPELINES
}

\author{
A. Fakroun and H. Benkreira ${ }^{1}$ \\ Department of Chemical Engineering \\ University of Bradford, UK
}

\begin{abstract}
Accepted for publication in Chemical Engineering Science in Sept 2019 3DOI:https://doi.org/10.1016/j.ces.2019.115212 Reference: CES 115212
\end{abstract}

\begin{abstract}
Waxy crude oils are pumped hot but upon power cut, pumping stops, the oil cools leading below the wax appearance temperature to precipitation of the wax and the formation of a gel throughout the pipe. In such a situation, what is the minimum pressure required to restart flow, not to merely deform the gel or break it? This paper provides a solution to this problem using microscopic observations under controlled cooling conditions and rheological data conducted in constant stress mode under controlled temperature and cooling conditions and restart experiments in laboratory pipelines replicating the rheometric conditions and deviations from them to inform large diameter operation in the field. Three important findings derive from the experimental data collected: (i) A fragmentation stress $\tau_{f}$, rather than the static stress $\tau_{s}$ that precedes it, is found to be the more accurate predictor of flow re-start pressures; (ii) Waxy crude oils gels exhibit true yield stress and yielding process but also show flow on application of the slightest stress below yielding; (iii) This flow, in the elastic region, is jagged rather than continuous suggesting a consolidation process of the crystals and their agglomerates forming the gel. In the broader context of the existence of a yield stress, the data presented here show that there is such a thing as a yield stress and the concepts of a yield stress and that everything flows are not mutually exclusive.
\end{abstract}

Key words: waxy crude oil, rheology, re-start pressure yield stress, crystallisation.

\section{INTRODUCTION}

Since its first commercial exploitation in the 1860s, crude oil has gone to transform the world in many ways, technologically, politically and environmentally. Most critically, apart from water, it has become the most important liquid pumped through hundreds thousands miles of pipelines. Currently, 98.3 million barrels of oil are transported every day through 0.59 million kilometres of pipelines, the world's longest crude oil pipeline being $3787 \mathrm{~km}$ long pumping 1.6 million barrels a day through 82 pumping stations from Edmonton to Montreal, Canada via Chicago, USA (E.I.A, 2018). Clearly, the cost associated with the pumping of crude oil is very large. The cost increases further when power or equipment failure causes the shutdown of the operation of the pipeline. When considering waxy crude oils, oils that contain significant quantities of dissolved paraffin wax or naphthenic hydrocarbons (Speight, 2015), typically 15 to $40 \mathrm{wt}$ \% , maintaining pumping becomes even more critical to the economics of the oil industry (waxy crude oils accounts about one third of the world oil production (World Energy Council, 2016 )).

In their original reservoir conditions, these oils are fluid, the temperatures being in the range 70$150^{\circ} \mathrm{C}$. Once out of the ground, the oils cools down; so in normal pipeline operations and to enable them to flow, waxy crude oils are heated and maintained at temperatures above their wax appearance

${ }^{1}$ corresponding author: Tel (01274) 383721 Fax (01274) 385700 Email H.Benkreira@bradford.ac.uk 
(precipitation) temperature $\left(\mathrm{T}_{\mathrm{WA}}\right)$. These $\mathrm{T}_{\mathrm{WA}}$ (also called cloud points) are generally quite high compared with ambient conditions, for example $39^{\circ} \mathrm{C}$ in the case of North Sea oil, $43^{\circ} \mathrm{C}$ for China Daqing oil and as much as $67^{\circ} \mathrm{C}$ for Libya Remal oil (Köka et al., 2018). When accidently, heating is cut off over prolonged periods of time or when the external ambient temperature drops drastically in the cold winter months, the oil cools rapidly, the solubility of the wax falls, the wax precipitates out and forms on the cold pipe wall a sponge like gel network of interlocking wax crystals trapping liquid oil (Visitin et al., 2005, Betancourt et al., 2007, Morozov et al., 2016). If the cooling situation is not remedied, over time the gel will age and harden, reducing the cross sectional area for flow and in severe cases nearly completely blocking the pipeline. Pigging or cutting out the plugged pipe section becomes a very expensive necessity (Southgate, 2004). The precipitation situation described above is aggravated when flow is interrupted following pumps failure, the oil now static in the pipeline cooling more rapidly. Restarting a gelled pipeline is thus a common problem in the oil industry which can be very expensive without a good understanding of the rheology of the cooled static gel to enable a correct prediction of an appropriate re-start pressure to be made. Because of the importance of the problem, gelled waxy crude oils have been extensively studied and from several perspectives, morphology (Kok et al., 1996, Singh et al., 2001, Chen et al., 2004, Visintin et al., 2008, Yi and Zhang, 2011, Lin et al., 2011), rheology (Wardhaugh and Boger, 1991a, 1991b, Rønningsen, 1992, Chang et al., 1998, Chang et al., 2000, da Silva and Coutinho, 2004, Kane et al., 2004, Venkatesan et al., 2005, Visintin et al., 2005, Visintin et al., 2008, Magda et al., 2009, Hou and Zhang, 2010, Dimitriou et al., 2011, Rønningsen, 2012, Marchesini et al., 2012, Tarcha et al., 2015, Andrade et al., 2015, Van Der Geest et al., 2017, Andrade et al., 2018) and modelling of pipe flow restart (Chang et al., 1999, Davidson et al., 2004, Vinay et al., 2006, Huang et al., 2011, Van Der Geest et al., 2015, Oliveira et al., 2015).

Studies on how waxy crude oils crystallise upon cooling, usually viewed using a transmission electron microscope, have confirmed that they follow classical nucleation and crystal growth mechanisms (Mullin, 2001) with structures growing into needle, disk or sheet like wax crystals of order 10-100 microns (depending on cooling rate) associating at low cooling rates into dense crystalline masses to form attractive colloid gels (Chen et al., 2004). The key observation from these studies is that the wax crystals and their aggregates are non-uniform in dimensions and shapes and trap solvent (wax free) oil in a locked colloid gel structure, the yielding of which is critically dependent on temperature, cooling rate and the rate at which the applied stress to destroy the structure is increased from zero (stress loading rate). Over the years, in tandem with the advances in rheometry, rheological studies of these gels have developed, enabling more precise measurements to be made. Because of the nature of gelled waxy crude oils, previous rheological studies had to confront the thorny issue of the yield stress concept (Barnes, 1999, Møller et al., 2006) and relax it into an engineering entity, a critical stress above which the gelled oil is deemed to show liquid-like behaviour or in the words of Barnes (2007) "observable or visible flow". To date, the original description (Fig. 1) of yielding proposed by the eminent rheologist Boger and his research associates (Chang et al., 1998) still holds: the gel first deforms elastically up to an elastic stress limit, $\tau_{e}$, then it creeps up to a static stress limit $\tau_{s}$ where it fractures. This end of creep, onset of failure or static stress limit $\tau_{s}$ is construed as being an appropriate yield stress, but the actual viscous flow region is beyond this limit, defined by a lower imaginary bound, the dynamic stress limit $\tau_{d}$, obtained by extrapolation to zero-shear rate. In this model deformation-flow, both $\tau_{e}$ and $\tau_{s}$ are dependent on the strength of the initial static network of wax crystals that forms upon cooling while $\tau_{d}$ is related to the concentration and size of the wax particles in the oils after the structure is completely destroyed. These stresses $\tau_{e}$ and $\tau_{s}$ are thus dependent on the temperature at which the static oil is cooled, the rate at which the temperature is dropped (cooling rate) and the rate at which the applied stress to destroy the network is increased from zero (stress loading rate). Implicitly, the dynamic stress $\tau_{d}$ will also be dependent on temperature and cooling rate as these parameters affect the size of the wax crystals that form upon cooling the static oil. As the stress loading rate affects how gel fracture proceeds in intensity and time, it will dictate whether the structure is destroyed to its ultimate crystal components or aggregates of these. Clearly, a fourth stress limit $\tau_{f}$ defining the end fracture or more specifically the end of fragmentation of the gel network becomes relevant and we define it here as the fragmentation stress. 
Since this original description, subsequent work has been to zoom in experimentally on these three limiting stresses $\tau_{e}, \tau_{s}$ and $\tau_{d}$ and measure more precisely their temperature, cooling and time dependency, using a variety of rheological techniques, constant shear rate, stress ramp, stress step increase, creep, and oscillatory shear. The merits of these various techniques in relation to predicting flow start-up of waxy crude oil in pipelines have been discussed in a recent comprehensive review by Chala et al. (2018) but it is evident that with nowadays advanced instruments which are capable at operating at very low stresses, the stress ramp technique is the most direct at extracting these limiting stresses. It also replicates actual pipeline start-up where the pump pressure is gradually increased at the rate that is the most effective at breaking the gel and inducing flow. In this research, the stress ramp technique is used.

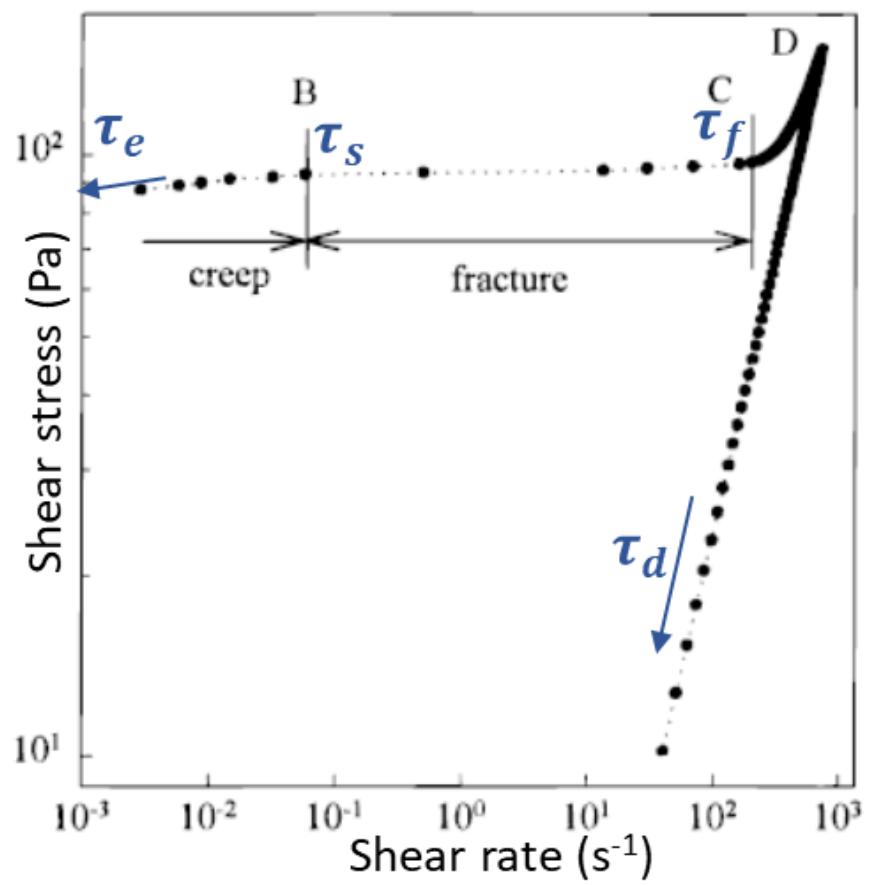

Fig. 1: Yielding characteristics of waxy crude oils as originally proposed by Chang et al., 1998.

The work we propose here revisits two aspects of the above description of yielding, born out of our experimental observations as we shall demonstrate later: first, about the elastic deformation and its continuity and second, the suitability of using the static stress as the appropriate flow re-start stress. We suggest that as these gels are made up of particles (crystals and their agglomerates) of different sizes bound together in a network trapping solvent oil, inter-particle interactions holding the network will differ in strength throughout the network causing it upon the application of the slightest stress to rearrange its conformation and gradually consolidate upon further small increases in the applied stress. In other words, we are suggesting that there is always flow (deformation) upon application of the slightest stress but the initial deformation is not a continuous elastic process in the classical sense. Our second suggestion is that the fragmentation stress, $\tau_{f}$, although not a yield stress per se (further discussion later) is an appropriate critical stress to use or at least consider for restart pipe flow calculations. The reason we give for this alternative is that only upon completion of fracture that all the oil trapped in the network is released- that is we have a liquid like flow only after we have reach $\tau_{f}$. Following from this, the aim of this work is to (1) measure, using the stress ramp technique, the entire deformation and flow below $\mathrm{T}_{\mathrm{WA}}$ of two waxy crude oils sourced from different fields and with very different wax content, (2) undertake these measurements for a range of temperatures, cooling rates and stress loading rates, (3) extract from these deformation-flow curves, using a rigourous data processing technique, the critical elasto-plasto-viscous markers, $\tau_{e}, \tau_{s}$ and 
$\tau_{d}$ discussed earlier but in addition the fourth limit, $\tau_{f}$, the end of fracture stress, noted in Chang et al. (1998) model but somehow ignored, (4) underpin the proposition of using $\tau_{f}$ rather than $\tau_{s}$ with data on restart pressures obtained in laboratory pipelines under conditions equivalent to the rheometric tests. In addition, we provide microscopic observations to support the physical model of the restart flow we propose and (5) discuss the work in the broader context of the yield stress concept. We note that rheological considerations are insufficient for a complete restart pressure prediction as the gel actually shrinks upon cooling, developing voids, making it thus compressible (Davidson et al., 2004, Vinay et al., 2006, Chala et al., 2018). Such aspects, though very important, are out of the scope of the present study.

\section{EXPERIMENTAL METHOD}

This investigation was carried out with two waxy crude oils supplied by BP and Agip Oil and their provenance was from the North Sea and Libya, thus labelled NSO and LBO respectively. These oils were chosen for their widely differing origin and wax content ( $45.5 \%$ for LBO compared to $15 \%$ for NSO) in order to give an element of fundamentality to the study with full details described by Fakroun PhD thesis (2018).

\subsection{Conditioning of the oil samples}

In order to ensure a base line for meaningful experiments, waxy crude oils must be brought to a state where the wax in them is fully dissolved and their prior deformation/flow history erased. To this end, the oil samples were heated well above their $\mathrm{T}_{\mathrm{WA}}$ at $100^{\circ} \mathrm{C}$ (the average reservoir temperatures of NSO and LBO) and thoroughly stirred in sealed pots with a turbine impeller at $80 \mathrm{rpm}, 30 \mathrm{~min}$ for NSO and $60 \mathrm{~min}$ for $\mathrm{LBO}$ as its wax content was much larger. The oils were then cooled down to temperatures $20^{\circ} \mathrm{C}$ higher than their $\mathrm{T}_{\mathrm{WA}}, 50^{\circ} \mathrm{C}$ for $\mathrm{NSO}$ and $80^{\circ} \mathrm{C}$ for $\mathrm{LBO}$ and stored at these respective temperatures in water baths ready for rheological and all other measurements. The conditioning parameters so chosen were arrived at by trial and error using rheological measurements to check that the data super-imposed. As shown in Fig. 2 , the results are staggering in the difference shown and demonstrate the necessity of conditioning as a prerequisite for a proper rheological study of waxy crude oils (Marchesini et al., 2012).

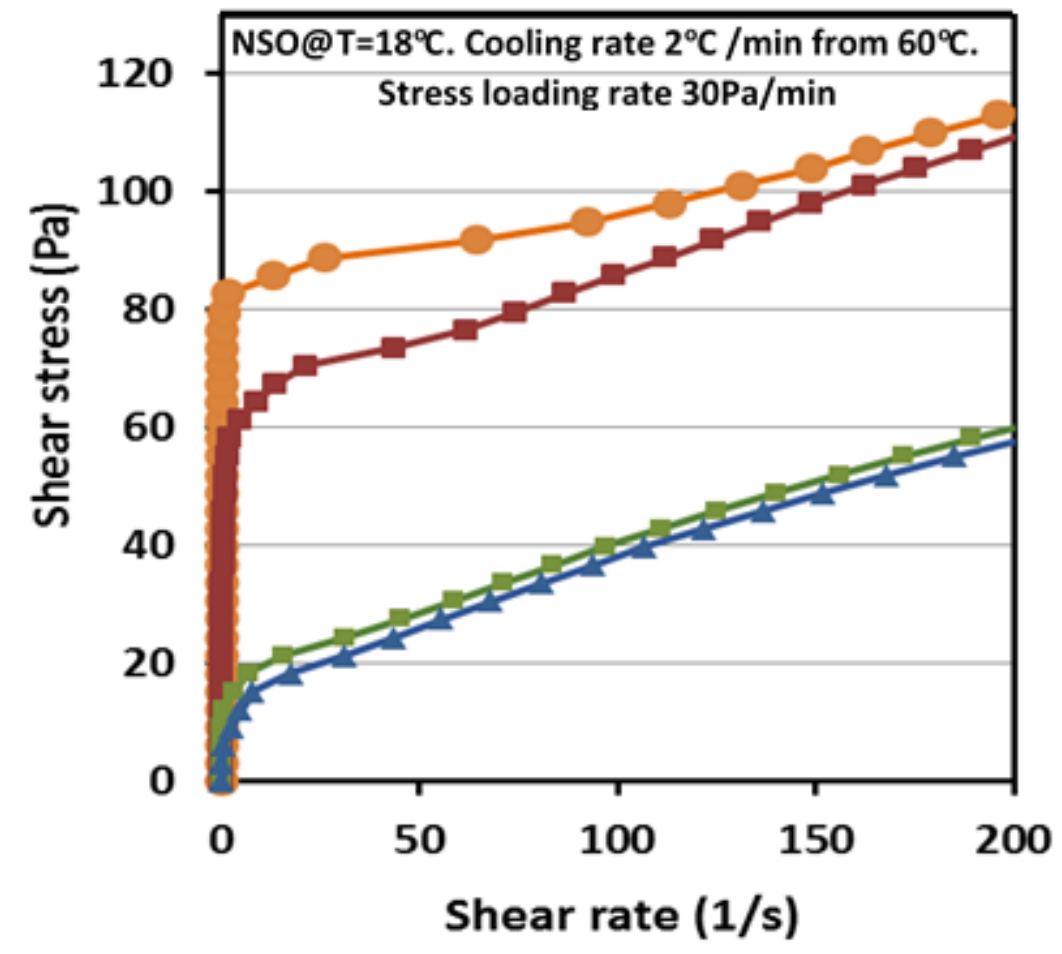

Fig. 2: Yielding of 2 conditioned $(\square, \boldsymbol{\Delta})$ and unconditioned $(\bullet, \square)$ samples. 
The repeatability of the conditioning procedure was checked by using two samples, each pre-treated using the same conditions described above, then performing three identical controlled stress rheological tests for each of the two samples. The repeatability of the tests was demonstrated by the values of $\tau_{e}, \tau_{s}$ and $\tau_{f}$ measured which showed a standard deviation of 1.5.

\subsection{The wax properties of NSO and LBO}

These are the wax appearance and disappearance temperatures ( $\mathrm{T}_{\mathrm{WA}}$ and $\left.\mathrm{T}_{\mathrm{WD}}\right)$ and the wax content determined from measuring heat flow in samples of the oils as the temperature was reduced ( $\left.\mathrm{T}_{\mathrm{WA}}\right)$ or increased ( $\left.\mathrm{T}_{\mathrm{WD}}\right)$ using a Differential Scanning Calorimeter (TA Instruments DSC Q20). As shown in Fig. $3 \mathrm{a}$, unlike NSO, the heat flow curve of LBO is flat some $20^{\circ} \mathrm{C}$ below $\mathrm{T}_{\mathrm{WA}}$ before surging towards a peak. This may be attributed to LBO containing a small amount of large molecules with a high number of hydrocarbons. The implication is that $\mathrm{LBO}$ will be still free flowing $20^{\circ} \mathrm{C}$ below its $\mathrm{T}_{\mathrm{WA}}$. Also, $\mathrm{T}_{\mathrm{WA}}$ and $\mathrm{T}_{\mathrm{WD}}$ were found to vary with the cooling/heating rates tested $\left(1,5,10\right.$ and $\left.15^{\circ} \mathrm{C} / \mathrm{min}\right)$ but not significantly. Specifically, and as shown in Table 1, $\mathrm{T}_{\mathrm{WA}}$ decreased with increasing cooling rate whereas $\mathrm{T}_{\mathrm{WD}}$ increased with increasing heating rate. The reason for this opposite behaviour is that as the cooling rate is increased, the wax precipitates at lower and lower $\mathrm{T}_{\mathrm{WA}}$ into smaller and smaller crystals but in larger numbers which require higher and higher $\mathrm{T}_{\mathrm{WD}}$ to dissolve back into the solvent oil.. The total wax content and the fraction of wax precipitated at a given temperature below $\mathrm{T}_{\mathrm{WA}}$ were determined using the total area and partial area respectively following the now widely used method of Chen et al. (2004). The wax content (see Fig. 3b) was found to be $16.3 \%$ for NSO and $46.4 \%$ for LBO very close to the specifications $(15.7 \%$ and $45.5 \%$ respectively) provided by the companies that supplied the oils. The wax content (see Fig. 3b) was found to be $16.3 \%$ for NSO and $46.4 \%$ for LBO very close to the specifications (15.7\% and $45.5 \%$ respectively) provided by the companies that supplied the oils.

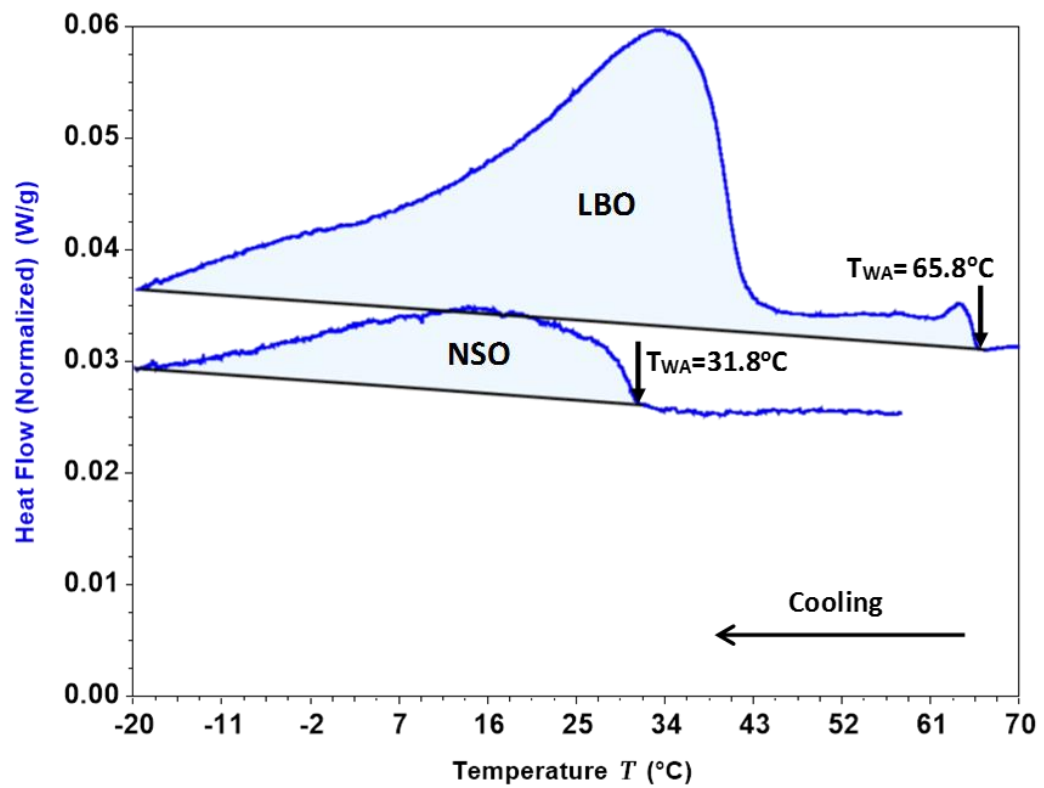

Fig. 3a: DSC heat flow curves of LBO and NSO measured at cooling rate of $0.5^{\circ} \mathrm{C} / \mathrm{min}$. 
Table 1: Variation of $\mathrm{T}_{\mathrm{WA}}$ and $\mathrm{T}_{\mathrm{WD}}$ for the two oils tested.

\begin{tabular}{|c|c|c|c|c|}
\hline \multirow{2}{*}{$\begin{array}{c}\text { Cooling/Heating } \\
\text { Rate ( }\end{array}$} & \multicolumn{2}{|c|}{$\mathrm{T}_{\mathrm{WA}}\left({ }^{\circ} \mathrm{C}\right)$} & \multicolumn{2}{c|}{$\mathrm{T}_{\mathrm{WD}}\left({ }^{\circ} \mathrm{C}\right)$} \\
\cline { 2 - 5 } & LBO & NSO & LBO & NSO \\
\hline $\mathbf{5}$ & 62.7 & 30.3 & 61.9 & 36.3 \\
\hline $\mathbf{1 0}$ & 61.8 & 27.5 & 62.4 & 37.8 \\
\hline $\mathbf{1 5}$ & 60.4 & 26.4 & 64.2 & 39.9 \\
\hline
\end{tabular}

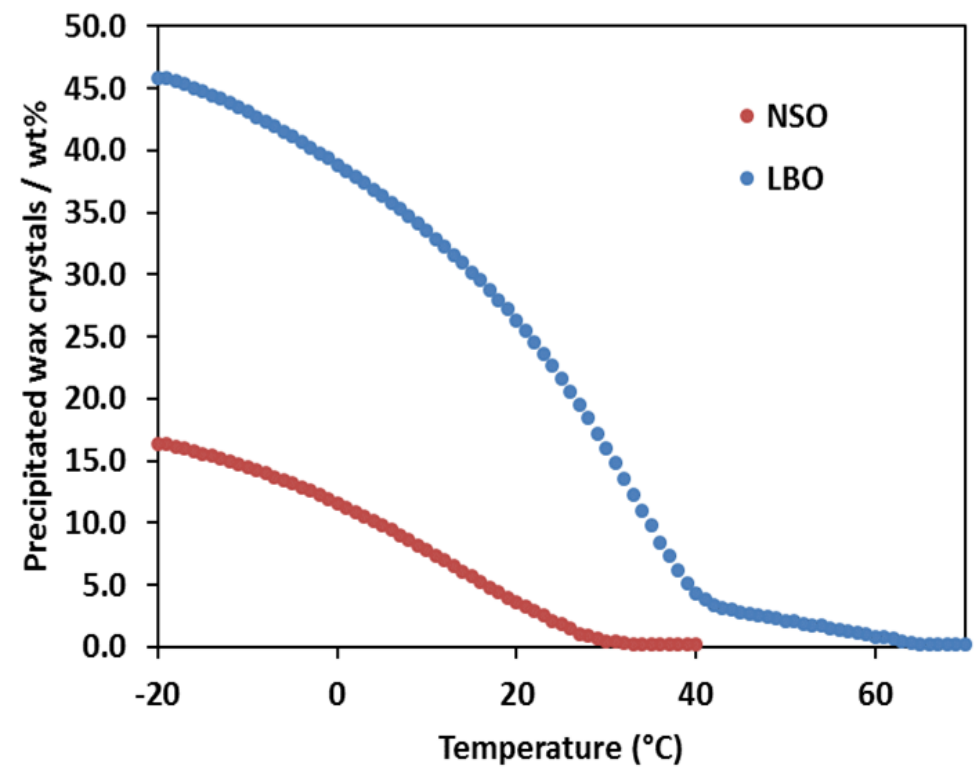

Fig. 3b.: Precipitated wax vs. temperature for $\mathrm{NSO}$ and $\mathrm{LBO}$ at $0.5^{\circ} \mathrm{C} / \mathrm{min}$ cooling rate.

With regard to the structures of gels formation upon cooling, we viewed these under a hot stage cross polarised microscope (THMS600, Zeiss, USA) connected to a Peltier heating/cooling unit. As shown in Fig. 4a for $\mathrm{LBO}$ at cooling rate of $0.5^{\circ} \mathrm{C} / \mathrm{min}$, initially precipitation is partial and segregated and as the temperature is decreased, more wax is precipitated, the wax crystals becoming more connected until above a critical temperature, a gel forms, in the case of $\mathrm{LBO}$ at $\mathrm{T}=30^{\circ} \mathrm{C}$. The gels that finally formed showed a solvent (wax free) oil trapped within an interconnected crystalline structure, needle like with NSO and more spheroid with LBO (see Fig. 4b). As for the dependence on cooling rate, the wax crystals observed, with both LBO and NSO, were fewer, larger and more interconnected at the low cooling rates than at high cooling rates where there were more numerous, much smaller and appeared looser within the gel structure. The interconnectivity of larger crystals at low cooling rates, suggest that low cooling rates lead to stronger gel structures. Conversely, the looseness of the structure observed at high cooling rates suggests that high cooling rates lead to weaker gel structures. These changes in structural features are evident from Fig. $4 \mathrm{c}$ of LBO samples cooled from $80^{\circ} \mathrm{C}$ down to $30^{\circ} \mathrm{C}$ at cooling rates of 5 and $0.5^{\circ} \mathrm{C} / \mathrm{min}$. They show clearly the changes in the structures just described. We will verify these observations, made also by previous workers (Chang et al., 2000 and Venkatesan et al., 2005 for example), later against rheological data. 


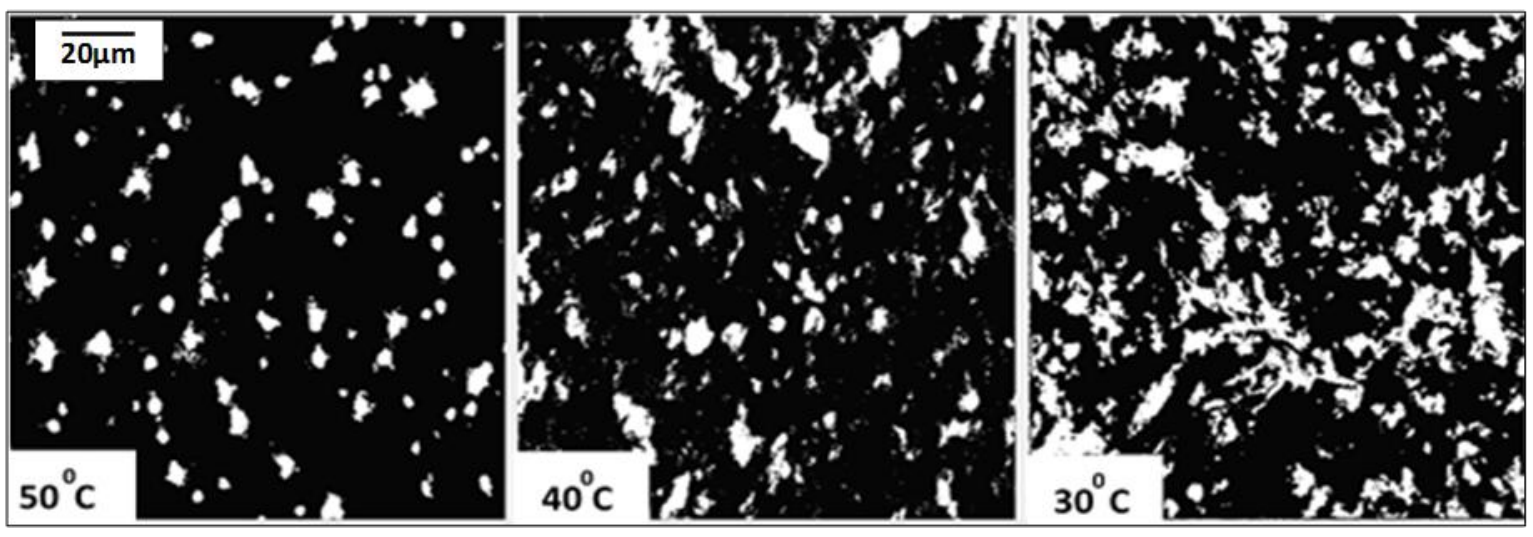

Fig. 4a: Crystallisation of $\mathrm{LBO}$ cooled from $80^{\circ} \mathrm{C}$ at $0.5^{\circ} \mathrm{C} / \mathrm{min}$ down to $\mathrm{T}=50,40$ and $30^{\circ} \mathrm{C}$.
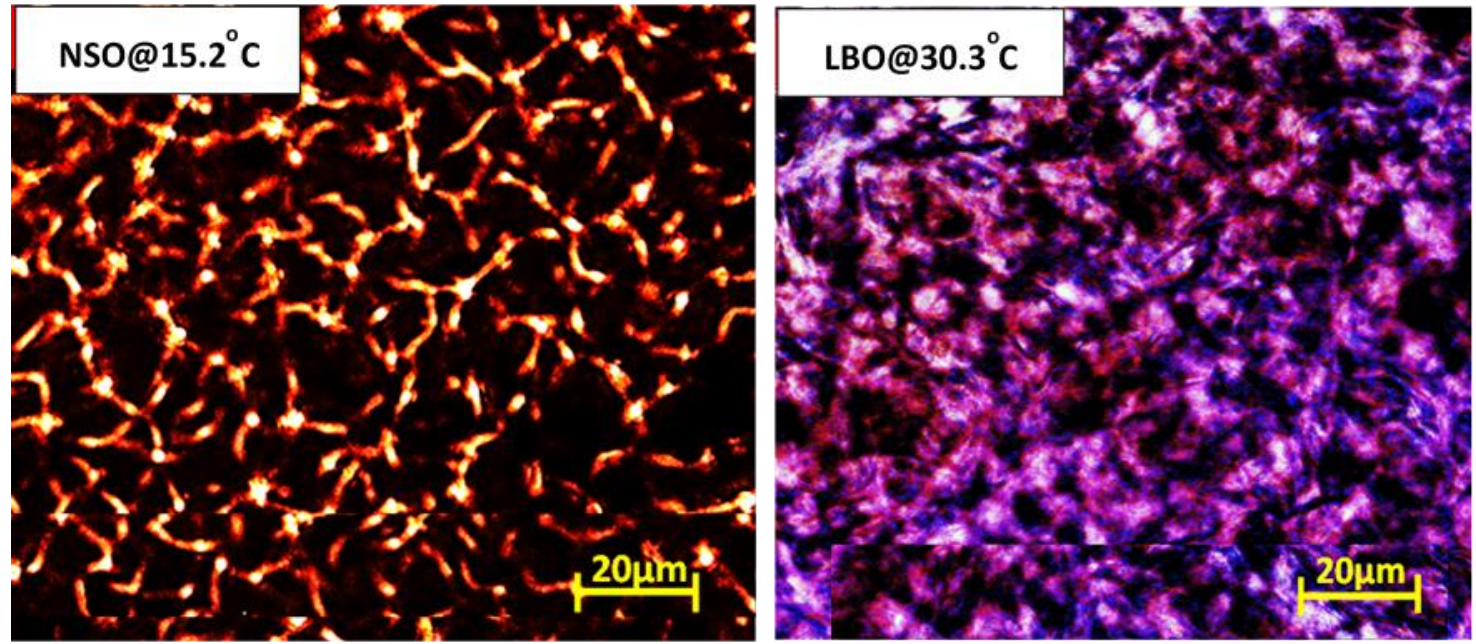

Fig. 4b: Crystallisation of NSO and LBO gels at $0.5^{\circ} \mathrm{C} / \mathrm{min}$ at 15.2 and $30.3^{\circ} \mathrm{C}$ respectively.
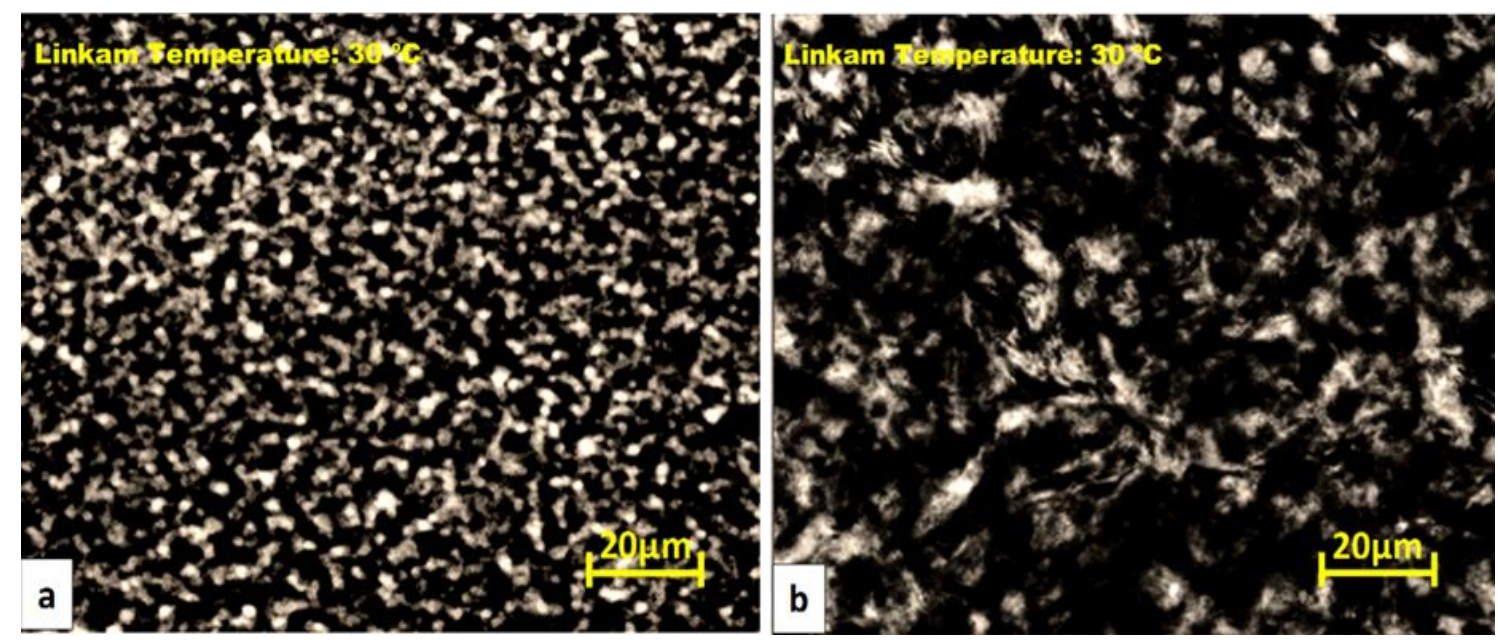

Fig. 4c: Crystallisation of LBO cooled from hot down to $30^{\circ} \mathrm{C}$ at (a) $5^{\circ} \mathrm{C} / \mathrm{min}$ and (b) $0.5^{\circ} \mathrm{C} / \mathrm{min}$. 
There is confusion in previous studies about gel strength and gel failure - compare the studies of Rønningsen (1992), Venkatesan et al. (2005), Chen et al. (2006), Lee et al. (2008), Lin et al. (2011 and those of Russell and Chapman (1971), Cawkwell et al. (1989), Webber (2001) and Guo et a. (2006). Strength as it is generally understood pertains to the cohesiveness of a structure whereas failure of a structure in a deformation/flow system may occur at the wall (adhesive) or in the bulk (cohesive) of the system. In a rheometer, cooling is always uniform (by definition) and so will be the gel structure. Slip being not permitted in a valid rheological experiment, the rheometer measures thus the cohesive strength. The same holds true in a very small diameter pipe as it is essentially a capillary rheometer. In an actual pipeline, the situation is complex as cooling is non uniform, leading to a non-uniform gel structure. We cannot speak in this situation of a one gel (cohesive) strength. Failure in such a situation will occur where the gel (cohesive) strength is at its weakest or at the wall if the gel adhesion to the wall is comparatively smaller than the cohesive strength anywhere else in the structure. The recent work of Andrade et al. (2018) substantiates such explanation. They found that there exists an optimal cooling rate that gives a uniformly cooled gel a maximum (cohesive) strength and this corresponds to the situation when the gel structure has the highest number of crystal links. Below and above this critical cooling rate, linkage between the crystal diminishes, reducing gel strength. Andrade et al. (2018) work however requires further verification as the gel strength was defined as the stress at the cross over point of $G^{\prime}$ and $G$ ' measured in oscillatory stress amplitude sweep after $1 \mathrm{hr}$ aging at a very low temperature $4^{\circ} \mathrm{C}$ of a model oil made up of mineral oil and $5 \%$ paraffin wax. Oil with higher wax content such as typical waxy crude oils may not exhibit such optimum gel strength as the number of crystal links will be very high and its effect less pronounced.

\subsection{Rheometry methodology}

The instrument used was the MCR 301 controlled stress rheometer from Anton Paar operating in the shear stress range $10^{-7}-10^{5} \mathrm{~Pa}$ and shear rate range $10^{-6}-10^{4} \mathrm{~s}^{-1}$ with Peltier temperature control of $\pm 0.5^{\circ} \mathrm{C}$ and cooling rates in a range varying from 0.01 to $6.5^{\circ} \mathrm{C} / \mathrm{min}$. The recommended (see Tarcha et al. (2015) study with different geometries) cone and plate geometry (stainless steel plate, diameter $25 \mathrm{~mm}$ and cone angle $\left.0.991^{\circ}\right)$ was used as this provided no slip, a uniform shear rate and uses a small sample $(0.60 \mathrm{ml})$ suitable for effective temperature control. The critical difference between this and earlier work (Chang et al., 1998) is the resolution in the shear stress/rate achievable, enabling to zoom into the elastic region and probing the creep-fracture region in very small steps and rates. As for the procedure, the following sequence was programmed: (i) rheometer plate set at the same initial temperature as the samples held in the seal pots $\left(80^{\circ} \mathrm{C}\right.$ for $\mathrm{LBO}$ and $50^{\circ} \mathrm{C}$ for $\left.\mathrm{NSO}\right)$ and held at this temperature for $10 \mathrm{~min}$; (ii) samples deposited on the plate and held at this initial temperature for $15 \mathrm{~min}$; (iii) a cooling rate is imposed to bring the temperature down to the test temperature; (iv) sample held at the test temperature for $10 \mathrm{~min}$; (v) a controlled stress sweep at very small linear increments typically of $0.5 \mathrm{~Pa}$ imposed from 0 to say $150 \mathrm{~Pa}$, well into the viscous regime and back to $0 \mathrm{~Pa}$. Such experiments were carried out in a range of cooling rates and stress ramp rates. To check for experimental errors, the tests were repeated three times. As remarked by Chang et al. (1998), with a strict control of the thermal and shear history of the samples, the measurements were found to be repeatable giving in our case yield stresses values of standard deviation of 1.5.

\section{$2.4 \quad$ Re-start pipeline rig}

As in industrial scale the pipeline diameters are large, cooling across them will be non-uniform unlike on a rheometer plate where only a thin film of sample is used.. Thus, the pipeline rig must reflect this duality: (i) provide uniform cooling rates across its diameter- here the pipeline is effectively a capillary rheometer and must have necessarily a very small diameter and (ii) assess the deviation from non-uniform cooling condition using larger diameter pipes, albeit of laboratory scale. Also by manipulating cooling rates and cooling holding times, we can approach or deviate from constant cooling rates conditions. Aside from these important considerations, the design of the rig is simple and consisted, as shown schematically in Fig.5, of: (i) a pipe of length to diameter ratio sufficient large to allow fully developed flow, means of (ii) uniformly heating the oil and maintaining it hot at a set temperature in the pipe, (iii) uniformly cooling it from this set temperature down to the test temperature at a set cooling rate and finally of (iv) restarting the 
flow from static conditions, observing its start point and measuring the corresponding restart pressure accurately. On the basis of this principle, the pipeline rig was built using $20 \mathrm{~m}$ long copper pipes, one of internal diameters $6.5 \mathrm{~mm}$, deemed to provide uniform cooling across its diameter and length and one of internal diameter twice the size, $13.5 \mathrm{~mm}$ to assess deviations from constant cooling rate conditions across its diameter. The inside wall roughness of both pipes was no more than $2 \mu \mathrm{m}$, the same roughness as that of the rheometer plate, as measured using a mechanical test (Taylor Hobson Precision, AMETEK Inc., USA). These pipes were jacketed (concentric pipes construction) by copper pipes of the same length, with a clearance of a few $\mathrm{mm}$ for controlled cooling or heating with water circulation through the annulus between the pipes. All external pipes were insulated. The temperatures on the pipe walls were controlled to within $\pm 0.5^{\circ} \mathrm{C}$ using thermocouples distributed every $1 \mathrm{~m}$ along the pipeline. The pressure drop along the pipe length was controlled and measured using a manometer placed at the inlet of the pipeline. The vertical section of the pipeline (50 $\mathrm{cm}$ long and glass made for observation) at the outlet was designed to compensate for the oil shrinkage due to voids formation during the cooling period. The shrinkage was observed to be equivalent to about $25 \mathrm{~cm}$ of the vertical glass pipe section or $1.25 \%$ of the total oil held $(20 \mathrm{~m})$.

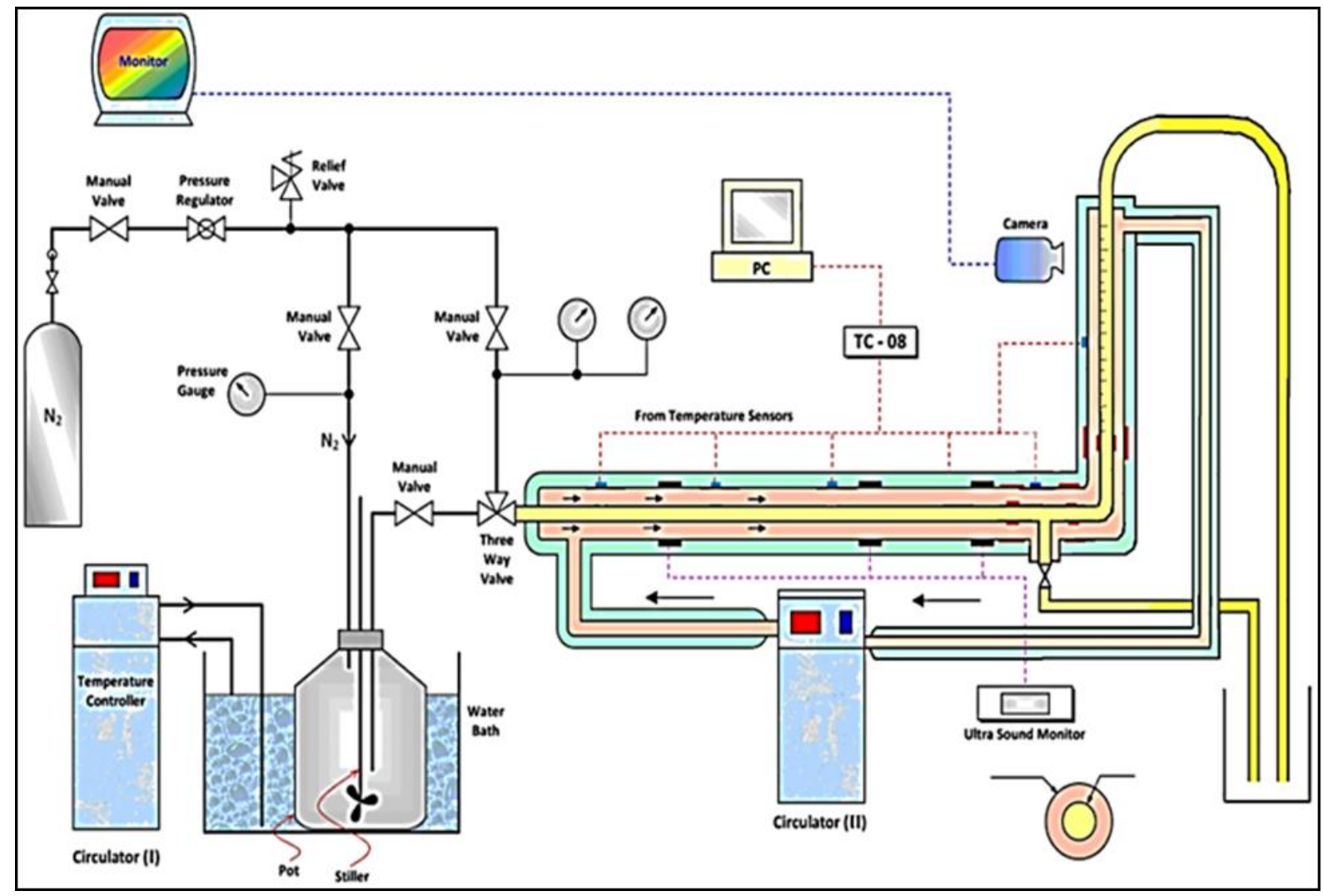

Fig. 5: Schematic of the laboratory model start-up pressure pipeline rig.

As for the operation of the pipeline, it was as follows. The oil sample was contained in a $2 \mathrm{~L}$ aluminium pot, conditioned as previously described and then kept in the water bath at a temperature $20^{\circ} \mathrm{C}$ above the $\mathrm{T}_{\mathrm{WA}}$ of the oils (i.e. at $50^{\circ} \mathrm{C}$ for $\mathrm{NSO}$ and $80^{\circ} \mathrm{C}$ for $\mathrm{LBO}$ ). The pipeline was heated to the same temperature, i.e. at $50^{\circ} \mathrm{C}$ for $\mathrm{NSO}$ and $80^{\circ} \mathrm{C}$ for $\mathrm{LBO}$. After that, the oil sample was pumped into the heated pipeline by pressurising the pot with nitrogen gas taken from a cylinder. Once inside the pipe, the immobile hot oil was left for 10 min to ensure a steady state base then a controlled cooling rate was applied down to the test temperature. Once the test temperature was reached, the oil was held at that temperature for a certain aging time to develop its gel structure. All these steps were conducted similarly to replicate the conditions 
adopted in the rheometer. The pipeline was then restarted by the application of pressurized nitrogen gas applied at the inlet of the pipe section holding the immobile oil gel plug at increments of 0.5 psi every $5 \mathrm{~s}$ (or other periods of time to vary the stress loading rate) until flow was observed to have started when the free meniscus in the glass end of the pipeline outlet moved up as viewed using a video camera connected to a monitor. The pressure drop $\Delta p$ at which the oil started to move was considered as being the re-start pressure, the equivalent of the critical or restart stress from the simple force balance:

$$
\Delta p \pi R^{2}=2 \pi R L \tau_{r s t}
$$

In Eq. (1), $\tau_{\text {rst }}$ is thus the semi-empirically predicted restart stress to be compared with the critical stresses $\tau_{e}, \tau_{s}, \tau_{f}$ and $\tau_{d}$ measured in the rheometer to assess our hypothesis (further details later) that $\tau_{f}$ is the appropriate critical stress to be used not $\tau_{s}$. In our experiments, no observations were made of the pipe interior; thus there was uncertainty on whether the gel broke at the wall or at a position inside the pipe. i.e. on the applicability of Eq. (1), the assumption being that a uniform cooling rate was set across the pipe section. In practice, with large diameter pipes, cooling will be non-uniform across the pipe. In the centre of the pipe cooling will be lower than at the wall. A large number of very small crystals will form on the wall creating a large interfacial area thus strong adhesion between the gel and the pipeline wall. However, such a gel structure of very small crystals is not strong in itself as we shall demonstrate later. The net result is that yielding will not occur at the wall but at a position away from it, at $R_{g}<R$. The position $R_{g}$ is difficult to pin and requires knowledge of the temperature distribution inside the pipe and its evolution with time. The corrected equation in such situations is thus:

$$
\Delta p \pi R_{g}^{2}=2 \pi R_{g} L \tau_{r s t}
$$

giving, as $R_{g}<R$, a $\tau_{r s t}$ that is lower than that predicted from Eq. (1). We will assess this deviation by performing experiments in a range of cooling rates $\left(0.05,0.1,0.2,0.5,1,2,5^{\circ} \mathrm{C} / \mathrm{min}\right)$, test temperature $(15$, $\left.25,35,40^{\circ} \mathrm{C}\right)$ and holding time $(5 \mathrm{~min}$ and $4 \mathrm{hr})$.

\section{RESULTS \& DISCUSSION}

\subsection{General features of the yielding measured}

Fig. 6a displays data for $\mathrm{NSO}$ at $\mathrm{T}=15^{\circ} \mathrm{C}$, cooled from $50^{\circ} \mathrm{C}$ at $0.5^{\circ} \mathrm{C} / \mathrm{min}$, then held at this temperature for 10 mins before applying a shear stress that was increased linearly from 0 to $150 \mathrm{~Pa}$ in 30 $\mathrm{Pa} / \mathrm{min}$ increments and then decreased back to zero in 1 min. Fig.6a drawn with a linear shear rate scale serves to show the broad elasto-visco-plastic and thixotropic nature of waxy crude oils when the stress is ramped up beyond yielding and into the viscous flow region then ramped down back to zero. Fig.6a however cannot resolve the initial features of yielding which are better brought out in Figs. $6 \mathrm{~b}$ and $6 \mathrm{c}$ with a logarithmic shear rate scale. In this figure, the yielding process is clearly shown depicting the initial elastic deformation which is followed by creep [A-B] and fracture [B-C] then viscous flow beyond point $\mathrm{C}$.

Interestingly, these figures show that the elastic region displays a jagged rather than a continuous variation. This jagged behaviour, observed with all samples, reflects the complexity of the gel structure and the way it deforms initially. As shown earlier in Fig.4, waxy crude oil gels are made up of crystals and their aggregates of different sizes bound together in a network trapping solvent oil. Inter-particle interactions holding the network will differ in strength throughout the network causing it, upon the application of the slightest stress, to rearrange its conformation, gradually consolidating until reaching the elastic limit $\tau_{e}$ where it begins to creep. No such observation has been reported with gelled crude oils before but recent research has shown the complexity of early yielding of other colloid gels and suspensions (Vassopoulos et al., 2007; Gibaud et al., 2009; Roy and Tirimkudulu, 2016). Moving to the creep region [A-B], the gradual increase in shear rate with increasing shear stress defines this region until a jump is observed, denoted in the figures by point B assigned to it a corresponding static yield stress $\tau_{s}$, the point signalling the first onset of fracture of the gel. Thereafter fracture develops throughout the gel leading to complete destruction of structure at point $\mathrm{C}$ denoting $\tau_{f}$, the gel fragmentation stress. This point demarks 
1 the beginning of the viscous region and realistically is a more appropriate flow restart stress than $\tau_{s}$. In

2 magnitude, $\tau_{f}$ is only fractionally higher than $\tau_{s}$. $\tau_{f}$ is of course not a yield stress (too higher shear rate

3 but jumped from a very low shear rate at $\tau_{s}$ ).

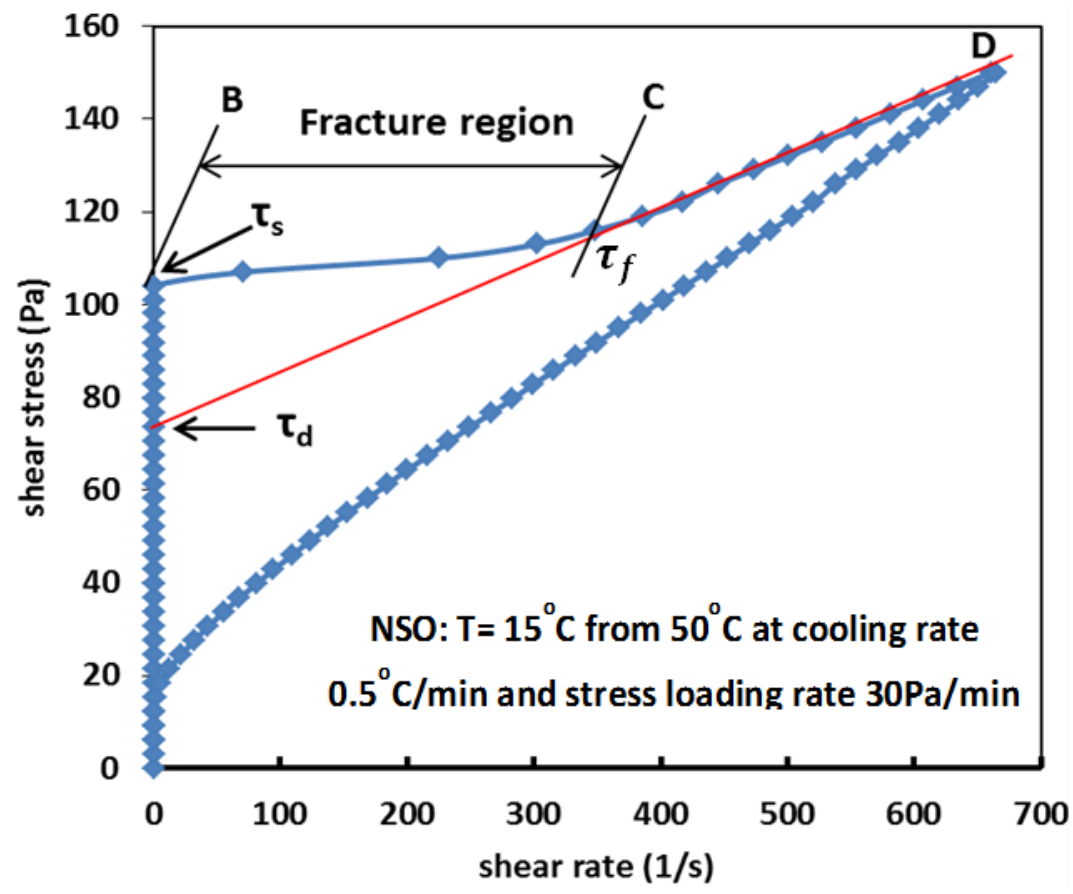

Fig. 6a: Controlled stress sweep of NSO.

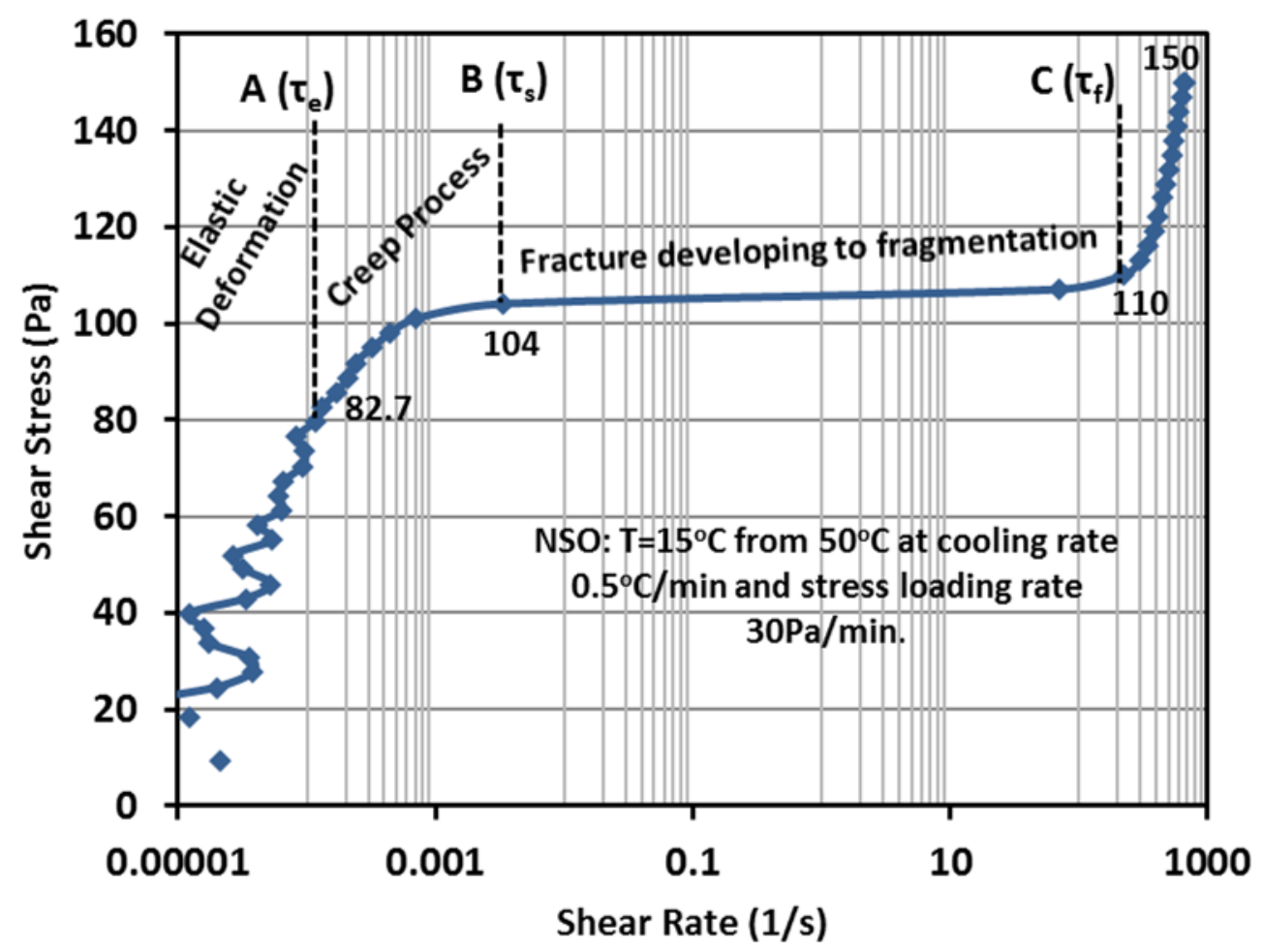

Fig. 6b: Upward stress sweep data of Fig.6a on an expanded log scale. 


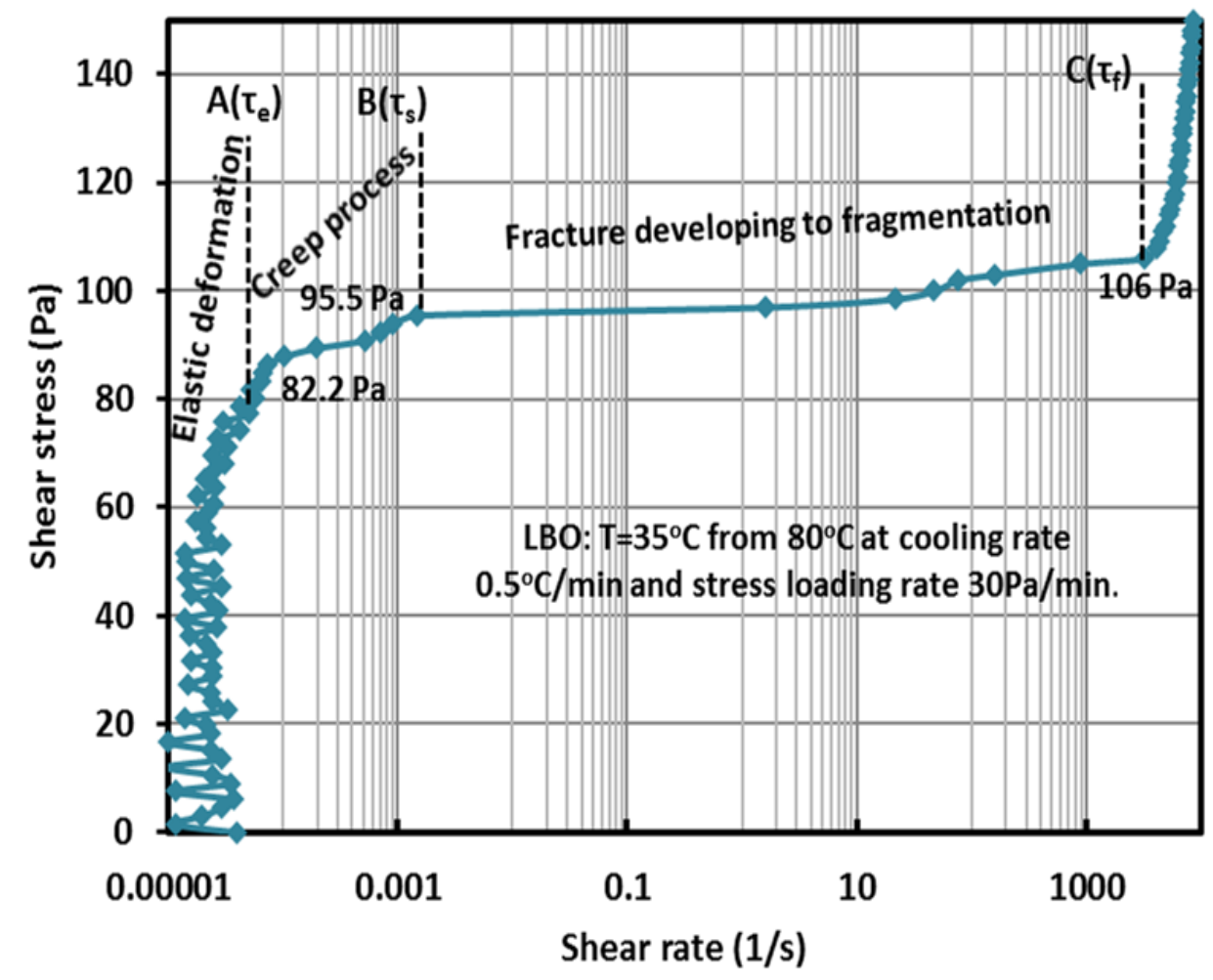

Fig. 6c: Upward stress sweep data of LBO.

The determination of $\tau_{e}, \tau_{s}$ and $\tau_{f}$ is mathematically resolved using plots of the derivative $d \dot{\gamma} / d \tau$ sometimes refers to as dynamic fluidity against shear stress as shown in Fig. 7 as a typical example of the data collected. $\tau_{e}$ is located as the shear stress where $d \dot{\gamma} / d \tau=0 ; \tau_{s}$ as the inflection point $\left(d^{2} \dot{\gamma} / d \tau^{2}=\infty\right)$ of the $\mathrm{AC}$ portion of the curve and $\mathrm{C}$ and $\tau_{f}$ as the maximum point $\left(d^{2} \dot{\gamma} / d \tau^{2}=0\right)$. As shown in Fig. 7, the fluidity of NSO jumps from essentially zero $\left(0.00012 \mathrm{~Pa}^{-1} \cdot \mathrm{s}^{-1}\right)$ below yielding to $51.6 \mathrm{~Pa}^{-1} \cdot \mathrm{s}^{-1}$ at fragmentation. In comparison (figure not shown), LBO jumps to $1142 \mathrm{~Pa}^{-1} \cdot \mathrm{s}^{-1}$ at fragmentation. Clearly with these large fluidity values the fragmentation stress cannot be construed as a yield stress. Rather, $\tau_{f}$ signals the onset of effective liquid-like flow with all the crystals and their aggregates now dispersed in the solvent oil. The inflection point or the static stress, $\tau_{s}$ where the jump commences is evidently a more appropriate yield stress. In comparison with $\tau_{f}$, the static yield point will have the crystals in a network about to fragment and as such it is a less effective predictor of the onset of liquid flow.

A further insight can be got by defining a fracture acceleration, $a_{f}$ through plotting shear rate $\dot{\gamma}$ against time and its time derivative $d \dot{\gamma} / d t$ against time as shown in Fig. 8. The large increase in shear rate or fracture speed and shear rate or fracture acceleration after yielding is now brought out very distinctly.

We see from this presentation of the data that the shear rate is initially essentially zero (but measurable as presented in Fig.6b, c above) until yielding commences, after which it increases sharply, then the increase diminishes. Correspondingly, the shear acceleration follows the same trend initially until after yielding it diverges, reaching a maximum then dropping. The maximum corresponds to the fragmentation spoked about earlier. As with fluidity, the shear rate at maximum shear acceleration is too large $\left(154.9 \mathrm{~s}^{-1}\right)$ and cannot be construed as to correspond to a yield stress. Rather it signals the start of a homogenous completely broken gel that will shear thin further with increasing stress. Following from this, Table 2 brings out the effect of wax type and content by comparing data at the same temperature, say 15 ${ }^{\circ} \mathrm{C}$. We know see that LBO is a solider structure, taking 747s to fragment compared with $222 \mathrm{~s}$ for NSO. However, judging from the high shear acceleration values of LBO at the start and end of fragmentation 
1 compared with those of NSO, the fragmentation of LBO is more catastrophic than that of NSO. It is

2 important to note that the comparison here is made at $15^{\circ} \mathrm{C}$, very much below the $\mathrm{T}_{\mathrm{WA}}$ of LBO $\left(65.8^{\circ} \mathrm{C}\right)$

3 than that of NSO $\left(31.8^{\circ} \mathrm{C}\right)$ where the states of the structures are very different, in a way making the 4 comparison not well defined.

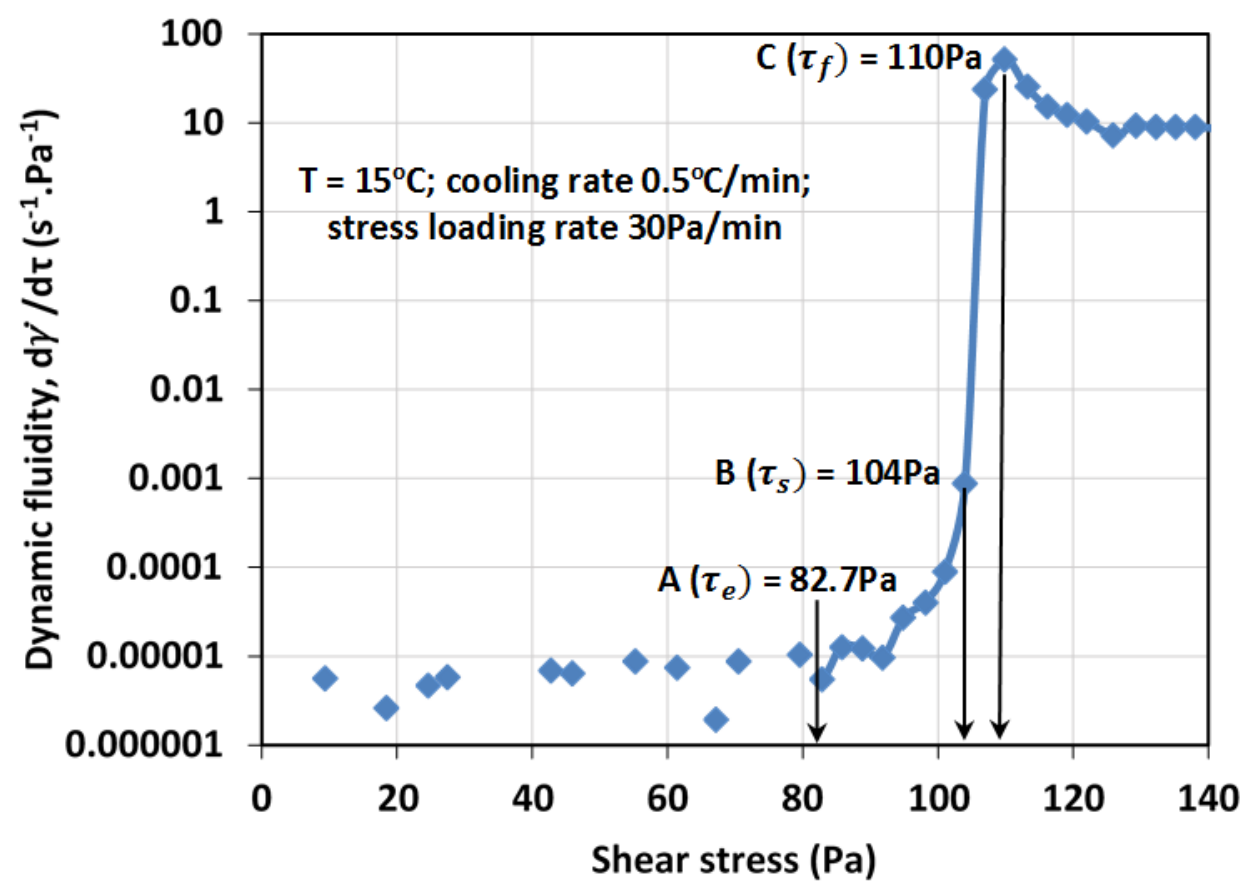

Fig. 7: Resolution of $\tau_{e}, \tau_{s}$ or $\tau_{f}$ using dynamic fluidity for NSO.

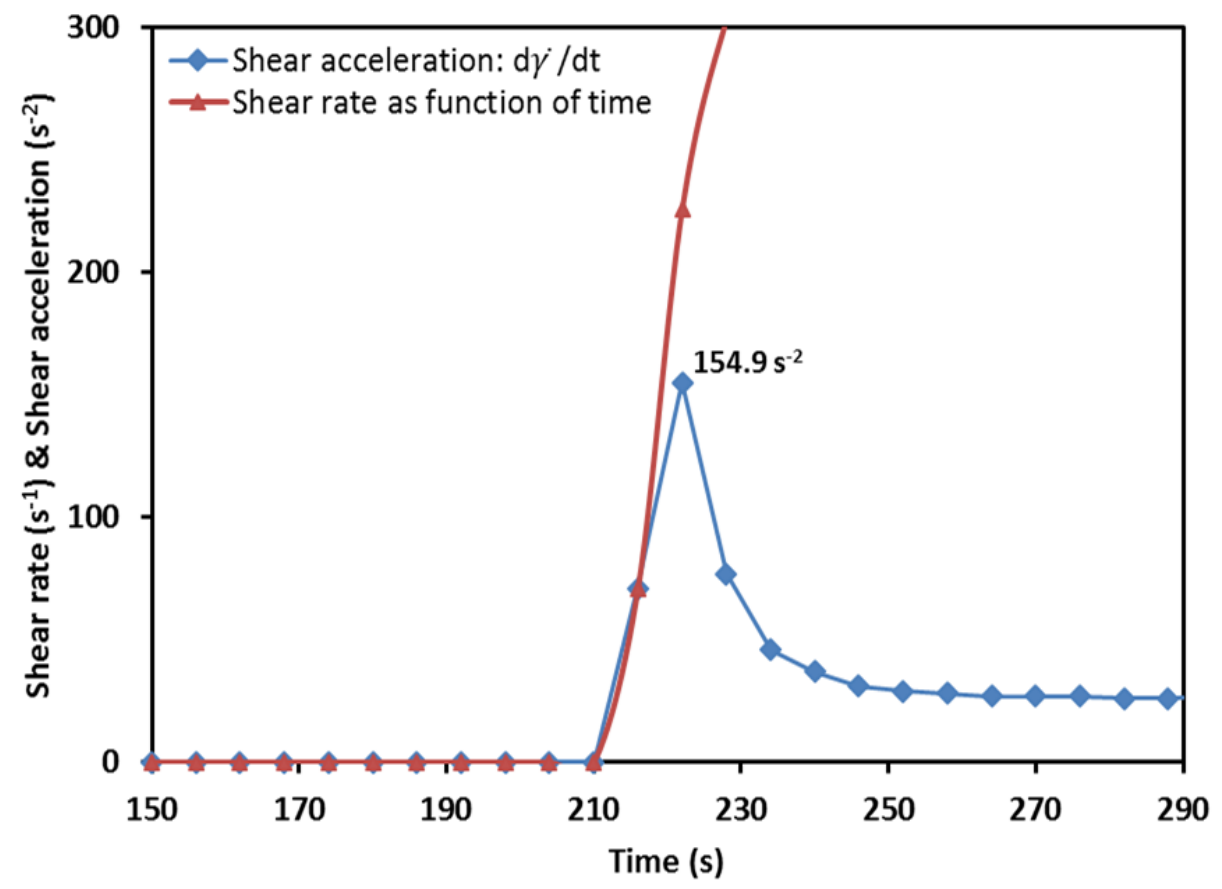

Fig. 8: Data of Fig. 7 transformed into shear acceleration and shear rate variations with time. 
Table 2: Comparison of yielding-creep-fracture of LBO and NSO tested under the same conditions.

\begin{tabular}{|c|c|c|c|c|}
\hline $\begin{array}{c}\mathrm{T}=\mathbf{1 5}{ }^{\circ} \mathrm{C} ; \mathbf{0 . 5} \\
\mathbf{3 0 P a} / \mathbf{C} / \mathbf{m i n}\end{array}$ & $\tau_{\boldsymbol{e}}, \boldsymbol{\tau}_{\boldsymbol{s}}, \boldsymbol{\tau}_{\boldsymbol{f}} \mathbf{( \mathrm { Pa } )}$ & $\boldsymbol{t}_{\boldsymbol{f}}(\mathbf{s})$ & $\begin{array}{c}\boldsymbol{a}_{\boldsymbol{f}}\left(\mathbf{s}^{-2}\right) \text { at start of } \\
\text { fracture }\end{array}$ & $\begin{array}{c}\boldsymbol{a}_{\boldsymbol{f}}\left(\mathbf{s}^{-2}\right) \text { at } \\
\text { fragmentation }\end{array}$ \\
\hline LBO $\left(\mathrm{T}_{\mathrm{WA}}=65.8^{\circ} \mathrm{C}\right)$ & $1030,1210,1295$ & 747 & 717 & 12510 \\
\hline NSO $\left(\mathrm{T}_{\mathrm{WA}}=31.8^{\circ} \mathrm{C}\right)$ & $83,104,110$ & 222 & 71.1 & 154.9 \\
\hline
\end{tabular}

In conclusion, from a yield stress perspective it is clear from the data presented that the fragmentation point experiences an excessively large shear rate and is not a yield stress. However, the increase in shear rate from the elastic $\left(\tau_{e}\right)$ and static yield stress $\left(\tau_{s}\right)$ to the fragmentation stress $\left(\tau_{f}\right)$ occurs so rapidly (with very small increases in stress) that $\tau_{f}$ represents a safe engineering flow restart stress to use to calculate the re-start pressure of gelled pipelines. Like $\tau_{e}$ and $\tau_{s}, \tau_{f}$ is uniquely defined and measurable. More interestingly, this data helps situate Barnes' (1999) "yield stress myth". The behaviour of waxy crude oil gels just described shows a true yield stress and yielding process $\left(\tau_{e} \rightarrow \tau_{s}\right)$ but the yielding does not initiate flow (deformation) which commences below $\tau_{e}$ and $\tau_{s}$, immediately on the application of the slightest stress. So indeed, in the words of Barnes' (1999), everything flows but as proved here there is such thing as a yield stress and the two concepts (yield stress and everything flows) are not mutually exclusive. With regard to the new fragmentation stress introduced in this analysis, we can view waxy crude oils as containing a range of polymer wax of different structures and molecular weights. Upon cooling, the gels that form are 3D networks of crystals of different sizes and shapes bound together by a range of intercrystals links (forces) holding the network together. The network is in a conformation volume that can change upon the application of a stress. Under the application of very low shear stresses, this conformation of crystals deforms and rearranges itself (jagged variation in the data) in an approximately Newtonian (elastic) manner up to the elastic limit, $\tau_{\mathrm{e}}$. During this initial stage, the inter-crystals links are not broken, but merely tensed elastically. At applied shear stresses larger than $\tau_{\mathrm{e}}$, the links will creep, until at the static shear stress, $\tau_{s}$, they begin to break. Because of the non-uniformity of the inter-crystals forces, the creep is not uniform throughout and not all the links will break at the same stress, the strongest links interlocking the structure requiring larger stresses to be broken, hence the definition of a beginning $\tau_{s}$ and an end $\tau_{f}$ of the fracture stage of the network. $\tau_{\mathrm{f}}$ could be termed the end of fracture rather than the fragmentation shear stress, the important point being that only at $\tau_{\mathrm{f}}$ would all the network have fragmented into single crystals or agglomerate of crystals. At this critical stress, there will be both single crystals and agglomerates dispersed into the solvent oil. At shear stresses larger than $\tau_{f}$, the agglomerates that have not broken may or may not break depending on the strength of the forces holding these particularly strong agglomerates and the extent and rate of shear. Elongational rather than shear stresses may be required to achieve complete dispersion. This simple mechanistic elastic-creep-fracture model must be seen in this integral perspective because the forces holding the crystals vary in their strengths, the crystals themselves varying in shapes, sizes and structures. If all the crystals were the same and the forces holding the same then $\tau_{\mathrm{f}}$ would not exist, all the fracture would occur at $\tau_{s}$. In relation to the important point of restart of the pipeline, it becomes clear then that $\tau_{\mathrm{f}}$ not $\tau_{\mathrm{s}}$ is the restart stress that must be applied.

\subsection{Effect of temperature on gel structure}

As expected and shown in Figs. 9a, b, temperature has a critical effect on structure. At the higher end $\left(30^{\circ} \mathrm{C}\right.$ for $\mathrm{NSO}$ and $45^{\circ} \mathrm{C}$ for $\left.\mathrm{LBO}\right)$, viscous flow prevails essentially. As the temperature is reduced, a stronger gel structure develops as indicated by the steep increase in $\tau_{e} \quad \tau_{s}$ and $\tau_{f}$ and the widening of the 
creep-fracture region. Also observed the consolidation in the elastic region discussed earlier; lower temperatures bringing out this feature more clearly, extending it to higher stresses.

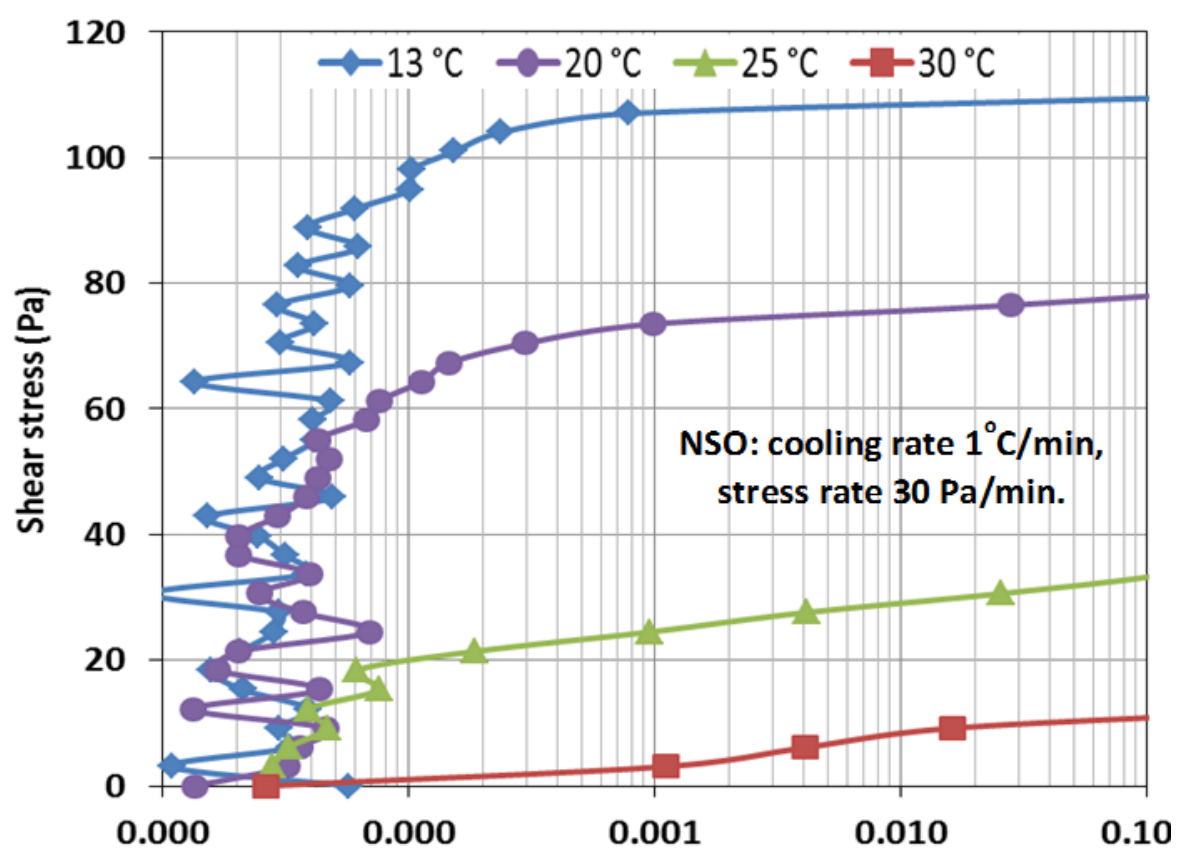

Fig. 9a: Gel strength development of NSO with reduced temperature.

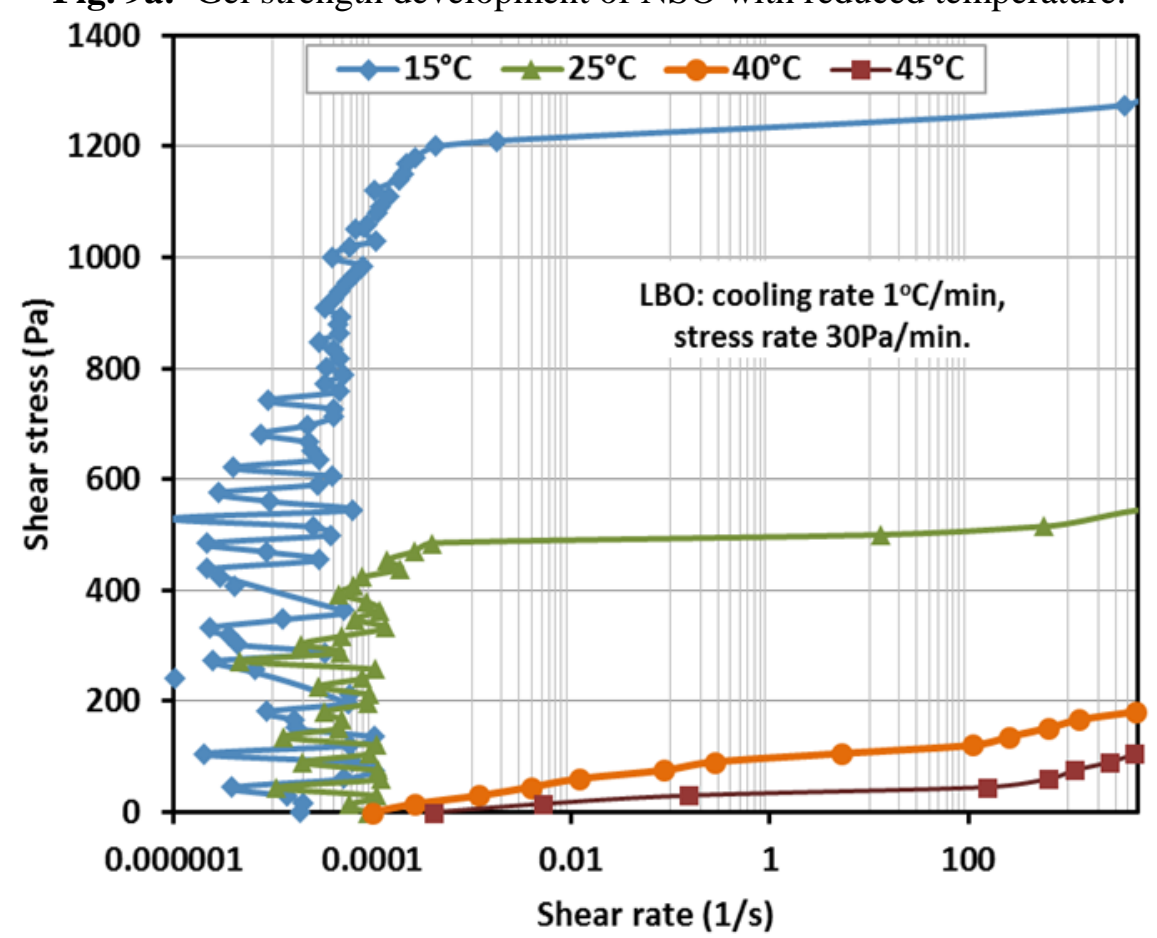

Fig. 9b: Gel strength development of LBO with reduced temperature.

Examining this data closely in Table 3 which brings in the time for fragmentation and the shear acceleration at fragmentation to quantify structure, we observe that a stronger structure develops as the temperature is reduced, taking longer time to fragment but with a higher shear acceleration at fragmentation. 
Table 3: Effect of temperature on gel structure (cooling rate $1{ }^{\circ} \mathrm{C} / \mathrm{min}$; stress rate $30 \mathrm{~Pa} / \mathrm{min}$ ).

\begin{tabular}{|c|c|c|c|c|c|c|c|}
\hline Crude oil & $\mathbf{T}\left({ }^{\circ} \mathbf{C}\right)$ & $\tau_{\boldsymbol{e}}(\mathrm{Pa})$ & $\boldsymbol{\tau}_{\boldsymbol{s}}(\mathrm{Pa})$ & $\boldsymbol{\tau}_{\boldsymbol{f}}(\mathrm{Pa})$ & $\boldsymbol{\tau}_{\boldsymbol{d}}(\mathbf{P a})$ & $\begin{array}{c}\boldsymbol{a}_{\boldsymbol{f}}\left(\mathbf{s}^{-2}\right) \text { at } \\
\text { fragmentation }\end{array}$ & $\boldsymbol{t}_{\boldsymbol{f}}(\mathbf{s})$ \\
\hline \multirow{4}{*}{$\begin{array}{c}\text { NSO } \\
\mathrm{T}_{\mathrm{WA}}=31.8^{\circ} \mathrm{C}\end{array}$} & 30 & 0.0 & 6.0 & 13 & 4 & 15 & 18 \\
\cline { 2 - 8 } & 25 & 18.6 & 24.5 & 35.2 & 15.5 & 33 & 45 \\
\cline { 2 - 8 } & 20 & 40.2 & 68.5 & 81.5 & 31 & 102 & 146 \\
\cline { 2 - 8 } & 13 & 73.4 & 107 & 123 & 57.3 & 165 & 325 \\
\hline \multirow{4}{*}{$\begin{array}{c}\text { LBO } \\
\mathrm{T}_{\mathrm{WA}}=65.8^{\circ} \mathrm{C}\end{array}$} & 45 & 0.0 & 9.0 & 21 & 6 & 365 & 68 \\
\cline { 2 - 8 } & 40 & 17.2 & 35.5 & 52.3 & 20.5 & 1021 & 123 \\
\cline { 2 - 8 } & 15 & 1030 & 1210 & 1295 & 395 & 12510 & 747 \\
\hline
\end{tabular}

\subsection{Effect of cooling rate on gel structure}

Here data are presented in the light of conflicting results from previous work which reports in some studies [Russell and Chapman, 1971; Perkins and Turner, 1971; Petrellis and Flumerfelt, 1973 and Cawkwell and Charles, 1989] that high cooling rates result in stronger gel structures and in other studies [Rønningsen, 1992; Chang et al., 2000 and R. Venkatesan et al., 2005] the opposite; strength being defined in these studies by the static yield stress. First we present in Fig. 10a examples of thixotropic loops we measured at varying cooling rates with LBO. The low cooling rate not only gives higher yielding-creepfracture stresses upon ramping up of the stress but also higher viscosities upon ramping down (as indicated by the slopes of the ramp down curves). This conforms with the microscopic observations discussed earlier suggesting that low cooling rates allow time for crystals to grow and interconnect into a compact network whereas high cooling rate results in smaller crystals assembling into a relatively looser network.

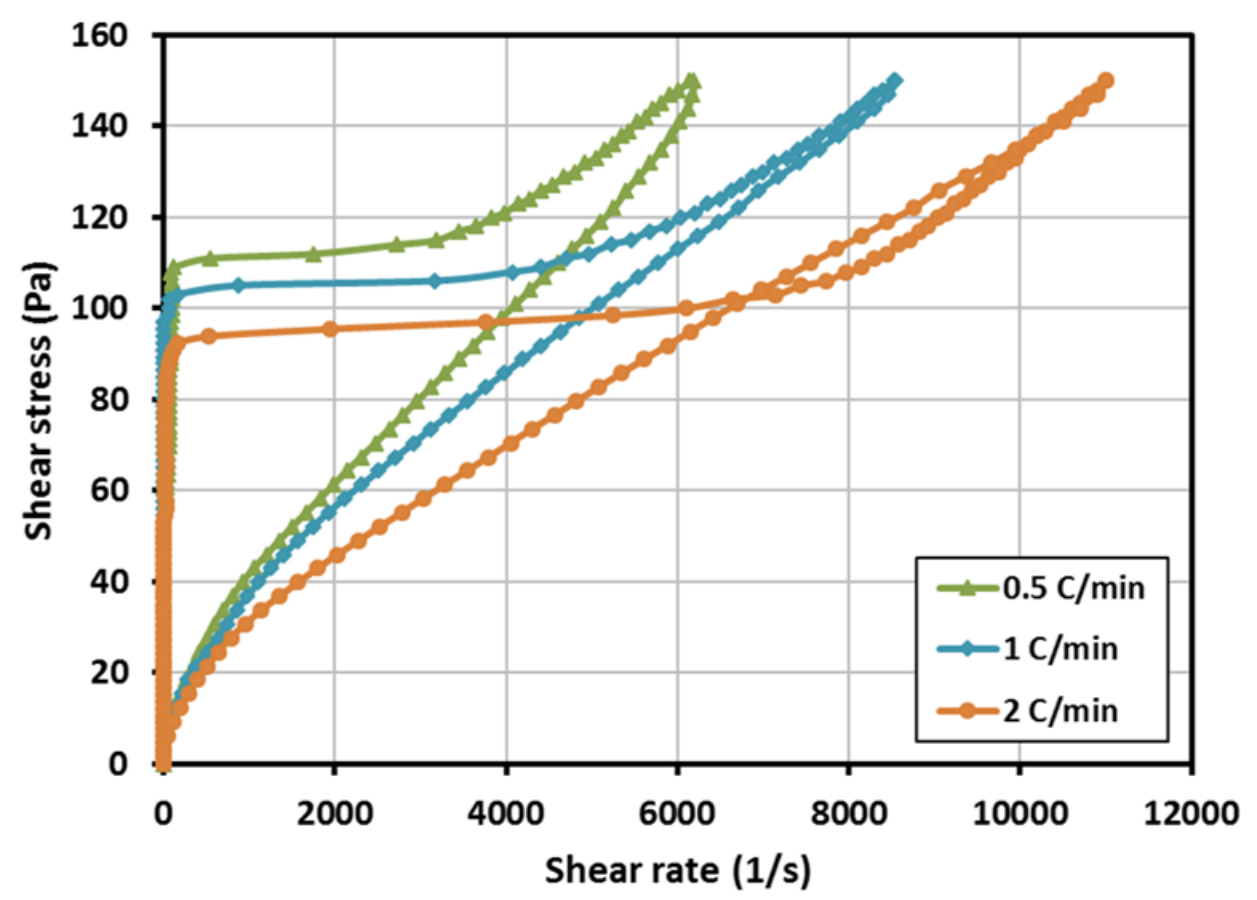

Fig. 10a: Effect of cooling rate on the thixotropy of $\mathrm{LBO}$ at $35^{\circ} \mathrm{C}$.

Limiting observations to the ramp-up part and resolving them to larger scales (Fig. 10b) and more accurately using the derivative method (Fig. 11 and Table 4), we observe clearly the decrease of all three 
critical stresses $\tau_{e}$ and $\tau_{s}, \tau_{f}$ with increasing cooling rate. Thus, fragmentation not only requires higher stresses as cooling rate is decreased, it also takes longer. Interestingly, the shear acceleration at fragmentation is also larger at the lower cooling rate suggesting a more catastrophic and effective fragmentation leading to a higher volume fraction of particulates (crystals and their small aggregates) in the follow-up more viscous flow as shown in Fig.10a.

Table 4: Effect of temperature on gel structure (cooling rate $1^{\circ} \mathrm{C} / \mathrm{min}$; stress rate $30 \mathrm{~Pa} / \mathrm{min}$ ).

\begin{tabular}{|c|c|c|c|c|c|c|}
\hline $\begin{array}{c}\text { Cooling } \\
\text { rate, } \\
\left({ }^{\circ} \mathbf{C} / \mathbf{m i n}\right)\end{array}$ & $\begin{array}{c}\text { Elastic-limit } \\
\text { yield stress } \\
(\mathrm{Pa})\end{array}$ & $\begin{array}{c}\text { Static } \\
\text { yield stress } \\
(\mathrm{Pa})\end{array}$ & $\begin{array}{c}\text { Fragmentation } \\
\text { yield stress } \\
(\mathbf{P a})\end{array}$ & $\begin{array}{c}\boldsymbol{a}_{\boldsymbol{f}}\left(\mathbf{s}^{-2}\right) \text { at } \\
\text { fragmentation }\end{array}$ & $\begin{array}{c}\boldsymbol{t}_{\boldsymbol{f}} \\
(\mathbf{s})\end{array}$ & $\begin{array}{c}\text { Dynamic } \\
\text { yield stress } \\
(\mathrm{Pa})\end{array}$ \\
\hline \multicolumn{7}{|c|}{$\mathrm{NSO}$ at $18^{\circ} \mathrm{C}$, cooled from $50^{\circ} \mathrm{C}$} \\
\hline 0.5 & 63.4 & 101 & 115 & 155 & 222 & 73.6 \\
\hline 1 & 43.1 & 73.5 & 96 & 123 & 192 & 57.3 \\
\hline 2 & 10.2 & 24.5 & 74 & 43 & 150 & 21.4 \\
\hline \multicolumn{7}{|c|}{$\mathrm{LBO}$ at $35^{\circ} \mathrm{C}$, cooled from $80^{\circ} \mathrm{C}$} \\
\hline 0.5 & 72.7 & 95.5 & 108 & 2284 & 497 & 67.8 \\
\hline 1 & 37.9 & 65.2 & 101 & 1810 & 455 & 47 \\
\hline 2 & 22.2 & 45.5 & 93 & 1212 & 287 & 15.1 \\
\hline
\end{tabular}

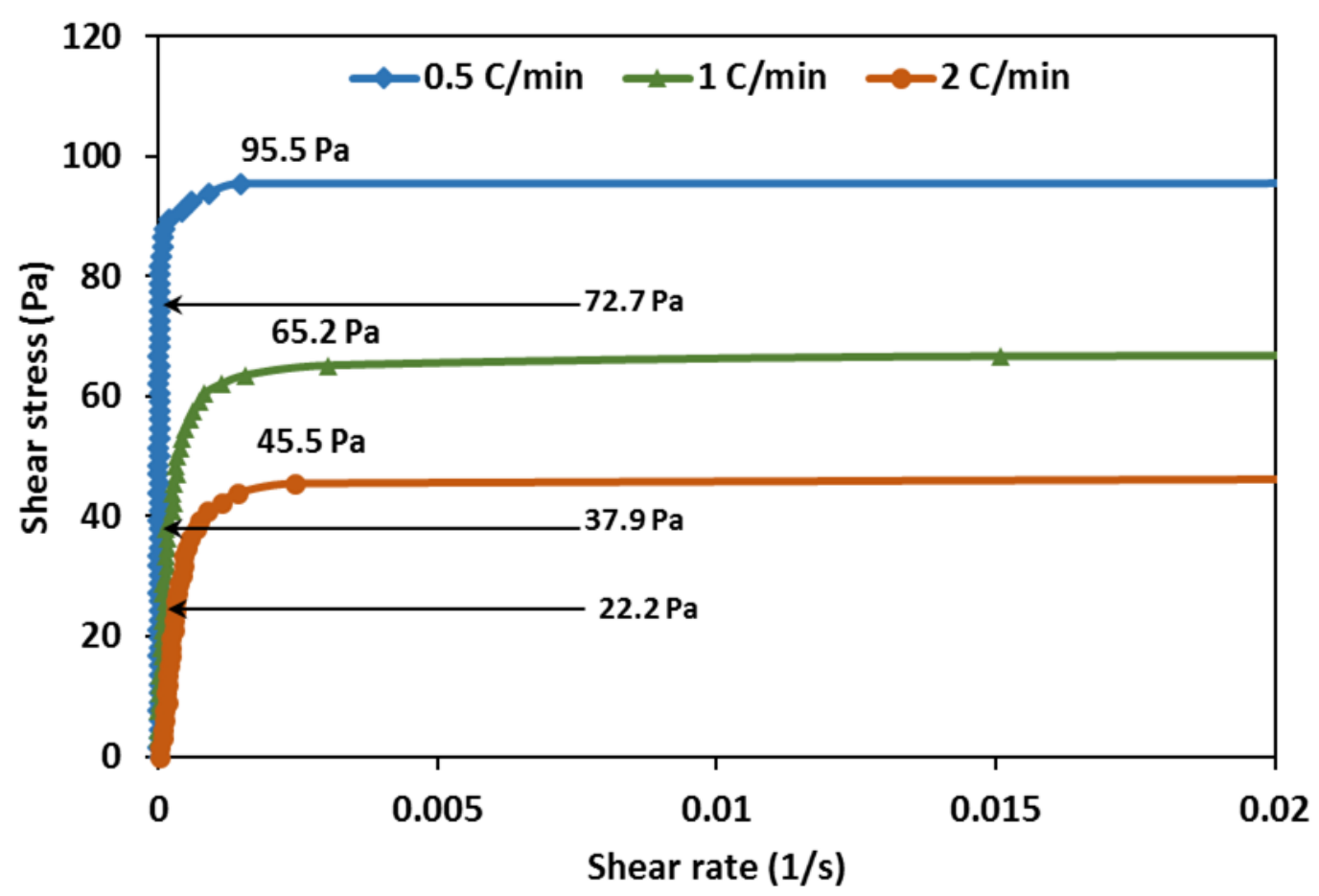

Fig. 10b: Strength development of LBO cooled to $35^{\circ} \mathrm{C}$ at various cooling rates. 
1

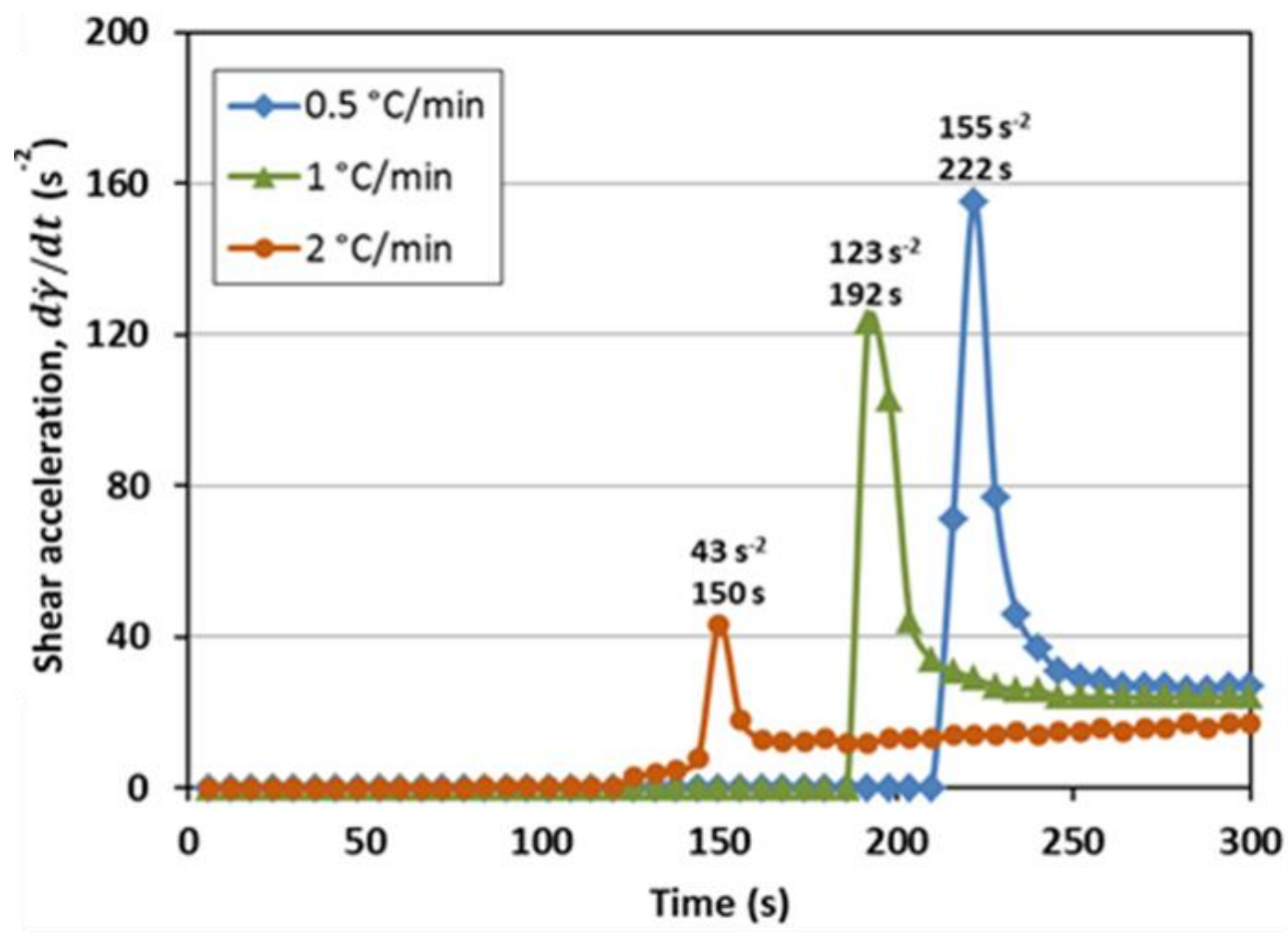

Fig.11: Variation of shear acceleration with cooling rate for NSO cooled to $18{ }^{0} \mathrm{C}$.

\subsection{Effect of stress loading rate on yielding}

As explained earlier, these gels possess static and fragmentation stresses that are stress rate dependent. This is reflected in the NSO data taken as an example (Fig. 12a, b).

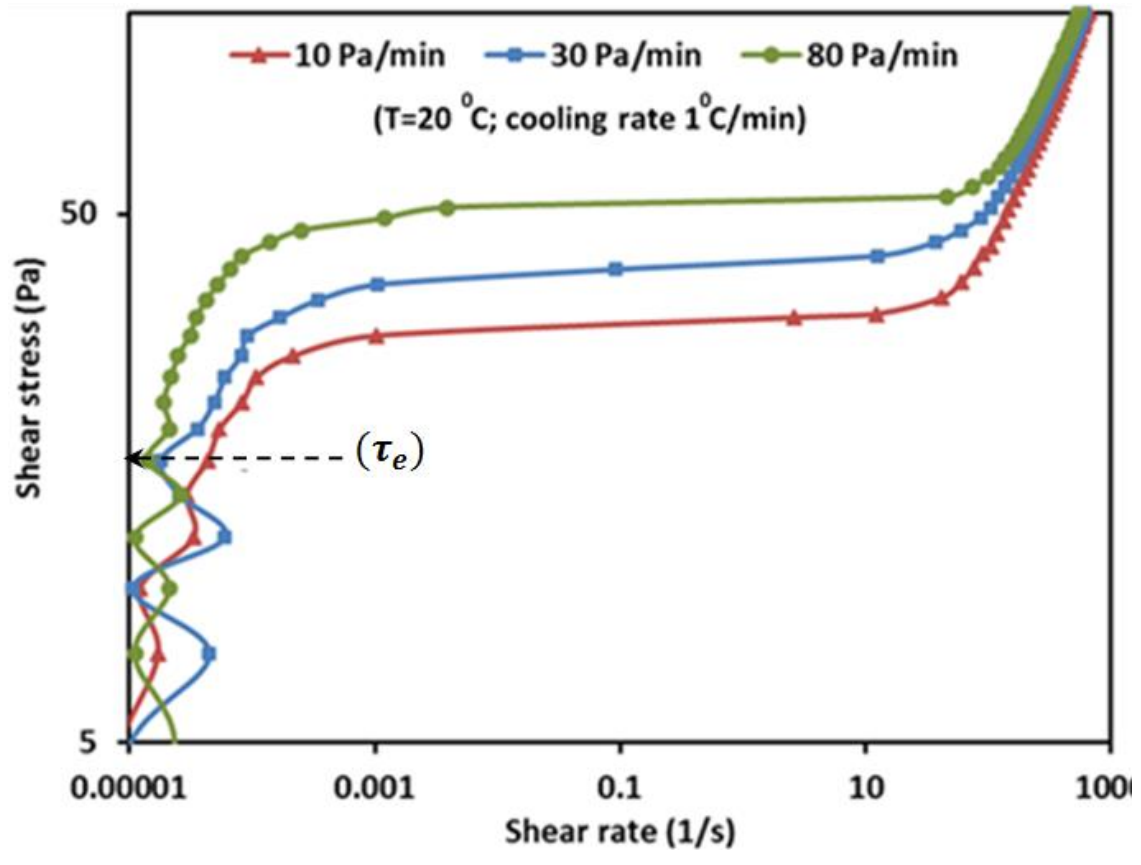

Fig. 12a: Effect of stress loading rate on yielding of NSO. 


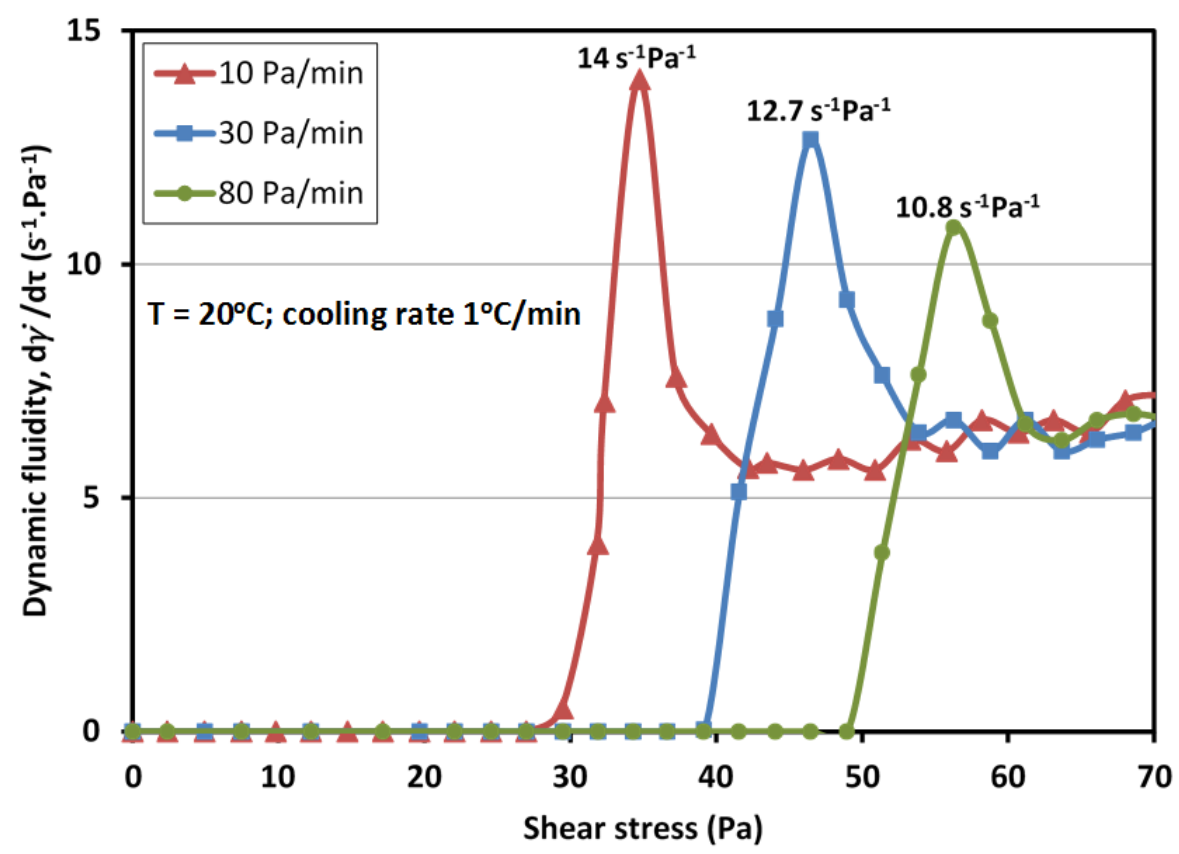

Fig. 12b: Effect of stress loading rate on NSO dynamic fluidity.

As shown in the above figures and in the summary data of Fig. 13, extracted from the derivative method, except for $\tau_{e}$ whose variation is negligible, $\tau_{s}, \tau_{f}$ and $\tau_{d}$ all show a significant increase with increasing stress rate. The increase in $\tau_{d}$ can be attributed to structural changes that occur after fragmentation affecting particle size and volume fraction in the viscous state. Fig. 12b shows precisely this with the fluidity at fragmentation decreasing with increasing stress rate from 14 to $10.8 \mathrm{~s}^{-1} \mathrm{~Pa}^{-1}$. Interesting also in Fig. 13, $\tau_{s}$ appears to converge towards the elastic stress $\tau_{e}$ when the stress rate is infinitely small. This suggests $\tau_{e}$ as being the lower limit of $\tau_{s}$ at the infinitely low stress loading rate, a most convenient observation for mathematical modelling as well as in practice.

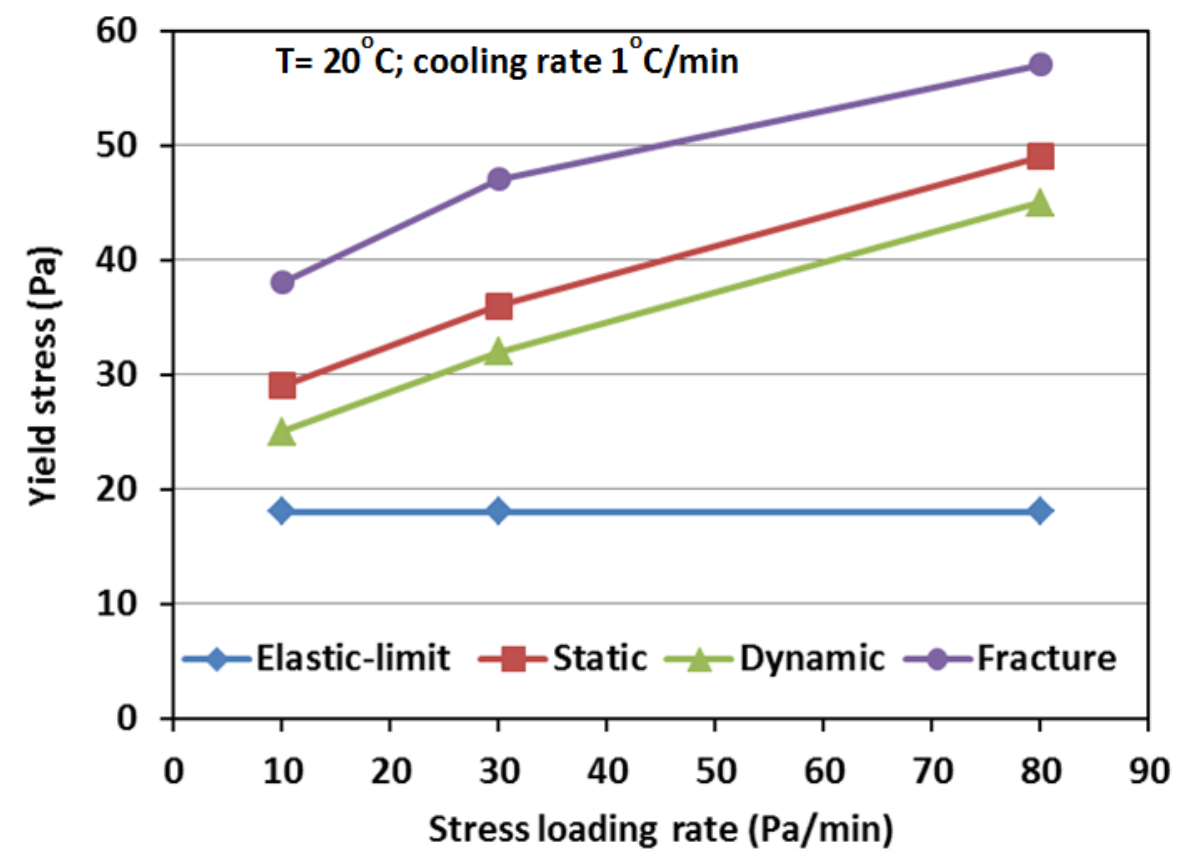

Fig. 13: Data of Fig. 12 summarised as $\tau_{e}, \tau_{s}, \tau_{f}$ and $\tau_{d}$ vs. stress loading rate. 


\subsection{Yielding predicted from restart pressures measured on the pipelines rig}

Fig. 14 gives a comparison of LBO static and fragmentation stresses $\tau_{s}$ and $\tau_{f}$ measured in the rheometer and restart stress predicted using Eq. (1) with restart pressures measured in the $6.5 \mathrm{~mm}$ and $13.5 \mathrm{~mm}$ diameter pipes for a range of temperatures and at a low cooling rate of $0.2{ }^{\circ} \mathrm{C} / \mathrm{min}$ typical of a normal cooling rate in the Libyan desert. Such a low cooling rate allows the formation of a uniform structure in the pipelines and by implication the restart stresses measured should tally with the stresses measured in the rheometer. To ensure that the same shear stress rates were used in both the pipeline and the rheometer, the pressure rates of increase applied in the pipeline rig ( 0.5 psi every $5 \mathrm{~s})$ were used to calculate the shear stress rates from the force balance Eq. (1). The shear stress rates so calculated were then used in the rheometer experiments. Fig. 14 presents the comparative data at this one stress rate loading of 13.4 $\mathrm{Pa} / \mathrm{min}$. It shows a better fit is observed with the fragmentation stress, $\tau_{f}$ than with the static stress $\tau_{s}$, justifying the hypothesis made earlier- that $\tau_{f}$ is a more appropriate pipe flow restart stress than $\tau_{s}$. Another observation from Fig. 14 is the measured and predicted stresses being essentially zero at $40^{\circ} \mathrm{C}$ in spite of the fact that $\mathrm{T}_{\mathrm{WA}}$ of $\mathrm{LBO}$ is $65.8^{\circ} \mathrm{C}$. Checking against the DSC flow curve (Fig. 3), we note that $\mathrm{T}_{\mathrm{WA}}=65.8^{\circ} \mathrm{C}$ signals indeed a precipitation of wax in LBO but only a small one, gathering real momentum only as the temperature is reduced below $40^{\circ} \mathrm{C}$.

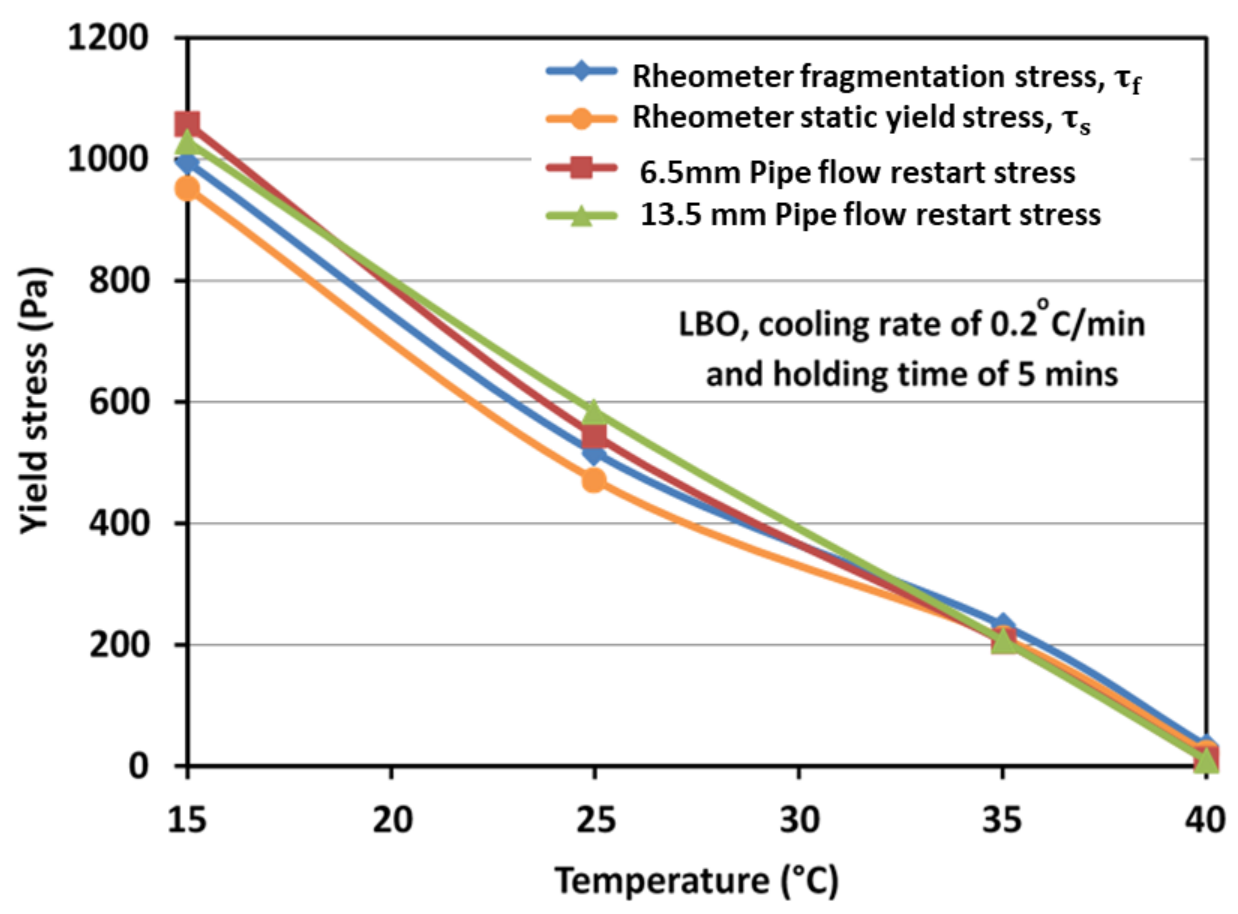

Fig. 14: Static and fracture yield stresses of LBO measured in the rheometer and model pipelines.

We now bring in the effect of cooling rate at a fixed temperature, increase it substantially over a very short time, say 5 mins to mimic with the $13.5 \mathrm{~mm}$ laboratory pipeline the formation of non-uniform gel structures that occur in industrial pipelines. As shown in Fig. 15a, when accentuating non-uniform cooling with wall cooling rates larger than $0.2{ }^{\circ} \mathrm{C} / \mathrm{min}$, we observe a divergence between the restart stress measured in the larger pipeline and $\tau_{s}$ and $\tau_{f}$ measured in the rheometer. This is to be expected as with large cooling rates the structures that form are non uniform. Rheological information alone are insufficient and must be coupled with a heat transfer analysis to find the pertinent temperature that help locates $R_{g}$.In situations when a long holding time is applied, say 4 hours, it is to be expected that temperature uniformity will be reached across the large diameter pipe, leading to more uniformity of gel strength across the pipe and to fracture at the wall. Also the longer holding time will enable the gel structure to develop even at the 
1 highest cooling rate (da Silva and Coutinho, 2004). The data in Fig. 15b show this to be the case with the 2 pipelines data in good agreement with the rheometer data, and again a better fit is observed with the 3 fragmentation stress, $\tau_{f}$ rather than with the static stress $\tau_{s}$, justifying the hypothesis made earlier- that $\tau_{f}$ 4 is a more appropriate pipe flow restart stress than $\tau_{s}$.

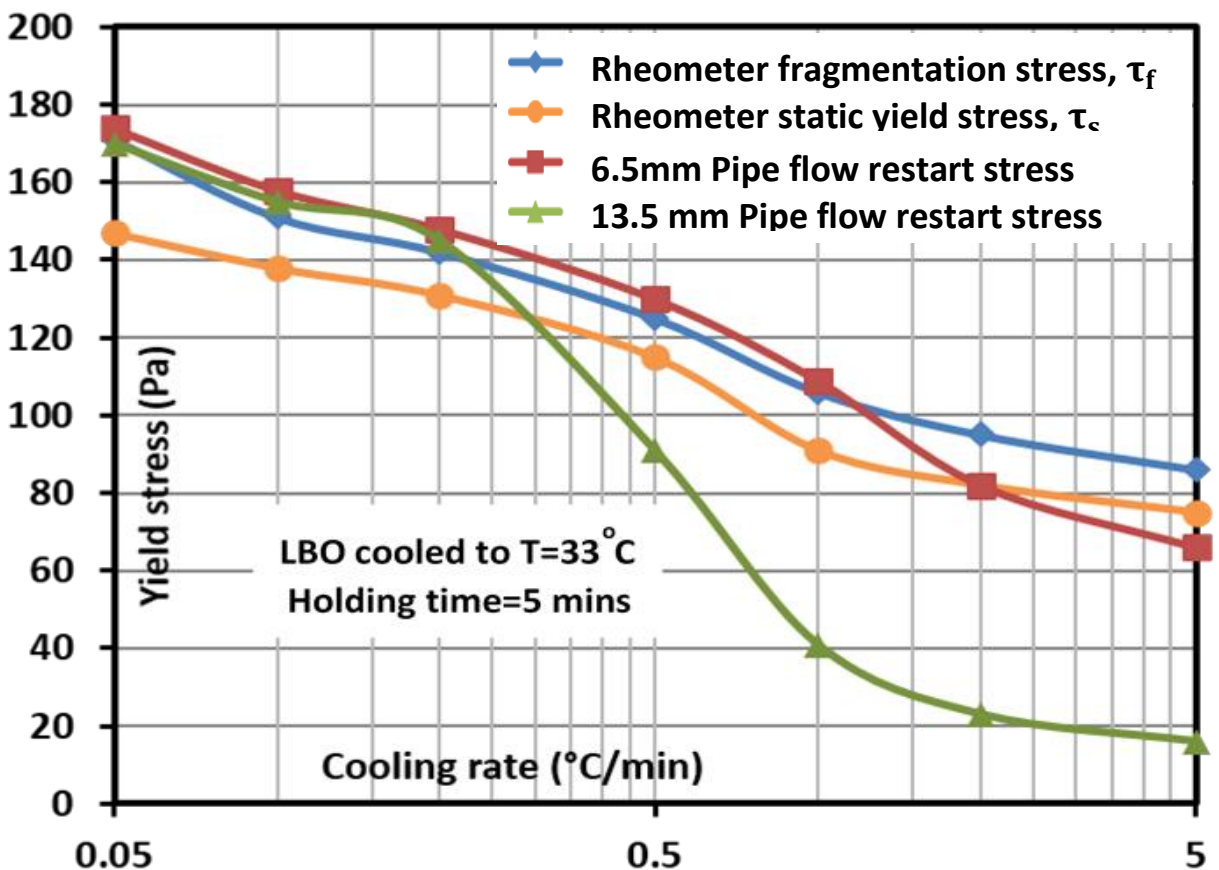

Fig. 15a: Static and fracture yield stresses of LBO measured at 5 mins holding time.

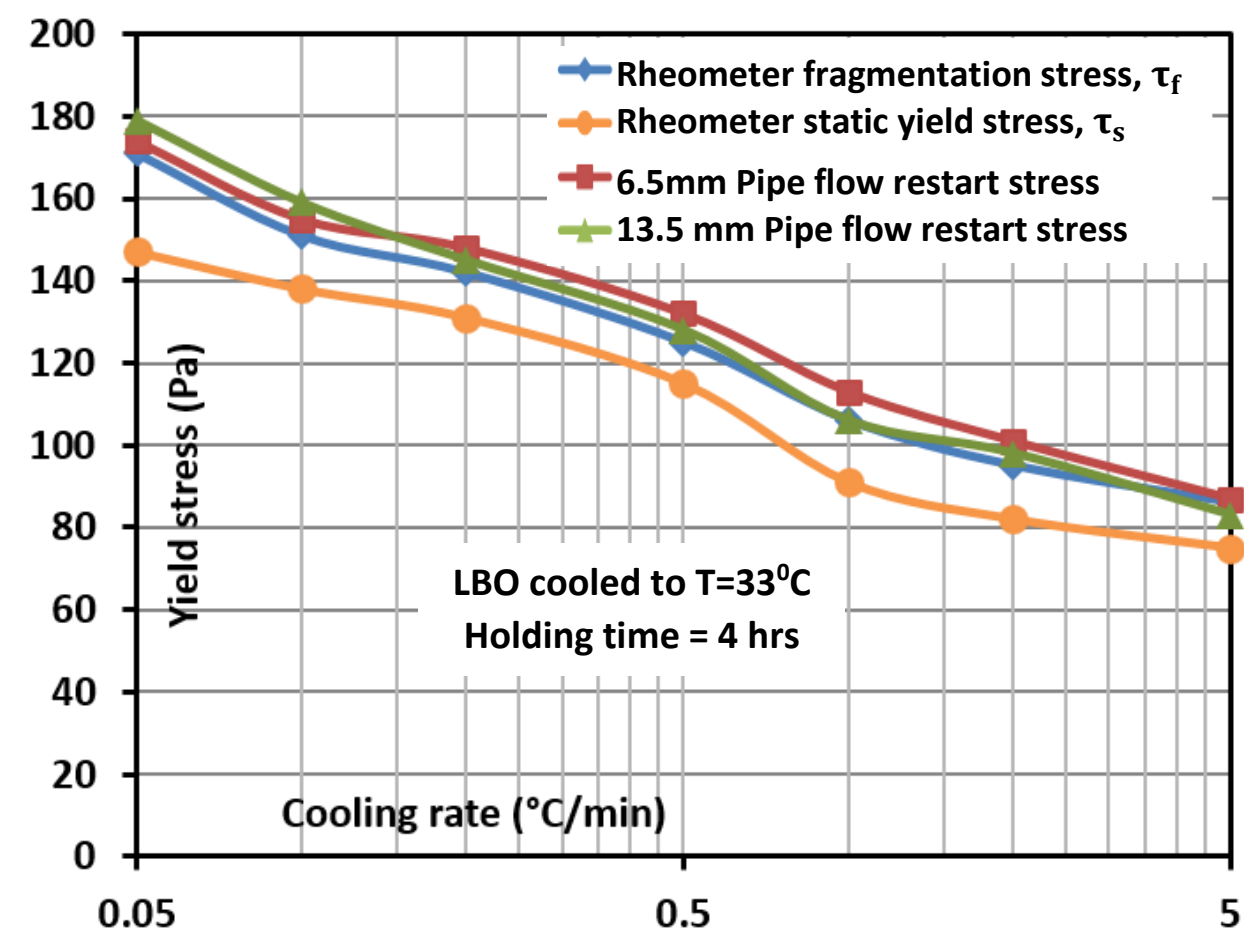

Fig. 15b: Static and fracture yield stresses of LBO measured at $4 \mathrm{hrs}$ holding time. 


\section{CONCLUSIONS}

Microscopic observations, DSC measurements and rheological data obtained in constant stress mode for a range of temperatures and cooling rates, with two very different waxy crude oils, have shown that waxy crude oils transform below their wax appearance temperature, $\mathrm{T}_{\mathrm{WA}}$ from viscous fluids into gel composed of wax crystals interconnected in a structure that traps solvent oil within its interstices. The strength of these structures depends on how far below $\mathrm{T}_{\mathrm{WA}}$ they are cooled to and on the rate of cooling they are subjected to. As revealed by the microscopic observations, fast cooling rates produce a seeded structure of very many fine crystals whereas slow cooling produces larger and fewer crystals. Controlled stress rheological data showed that these structures deform broadly as elastic-plastic-viscous materials but with subtle features at the very beginning (consolidation) and at the very end (fragmentation) before entering into viscous flow, brought out more distinctly as the temperature is reduced. By applying a derivative resolution method, we were able to extract accurately from the rheological data the elastic, $\tau_{e}$, static, $\tau_{s}$, fragmentation, $\tau_{f}$, and dynamic, $\tau_{d}$, stress limits. We observed that for a given temperature and a cooling rate, $\tau_{e}$ was essentially constant independent of stress rate. $\tau_{s}, \tau_{f}$, and $\tau_{d}$ however decreased markedly with decreasing stress rate with $\tau_{s}$ tending towards $\tau_{e}$ as the stress rate was reduced towards zero. Also, increased cooling rates in all cases decreased strength as measured by $\tau_{e}, \tau_{s}, \tau_{f}$, or $\tau_{d}$. In other words, the finer crystal structures that are produced at higher cooling rates are comparatively loosely interconnected than the larger crystal structures obtained at lower cooling rate.

Although the static stress limit $\tau_{s}$ is confirmed by this work to be a better descriptor of the yielding that occur from the elastic limit $\tau_{e}$, flow restart data obtained on laboratory pipelines under conditions similar to the rheometric experiments showed a better fit with the gel fragmentation stress $\tau_{f}$ than with the static stress $\tau_{s}$. At a given stress loading rate, $\tau_{f}$ is uniquely identified as being the stress at the gel complete fragmentation where the dynamic fluidity or its equivalent shear acceleration is maximal.

With regard to the fundamental issue of the existence of a yield stress (Barnes' (1999) “yield stress myth"), the data presented here show that waxy crude oil gels exhibit a true yield stress and yielding process $\left(\tau_{e} \rightarrow \tau_{s}\right)$ but the yielding does not initiate flow (deformation) which commences immediately on the application of the slightest stress $\left(0 \rightarrow \tau_{e}\right)$. So indeed, in the words of Barnes' (1999), everything flows but as proved here there is such thing as a yield stress and the two concepts, yield stress and everything flows, are not mutually exclusive. In this respect, we have extended Cheng's (1985) concept (see Fig. 6 of Barnes (1999)), somehow overlooked if not dismissed by Barnes (1999) much cited work.

As remarked in the discussion, the consolidation feature we report here has never been reported before and merits further investigation. Also rheology alone is insufficient to guide restart, a heat transfer analysis is required alongside it to determine the temperature profile in a pipeline to locate the gel front and how it migrates in time inside the pipe at a given temperature, cooling rate and holding time.

In conclusion, the significance of this work is twofold, (i) provides better guidance for the important industrial problem of restarting waxy crude oil gelled pipelines and (ii) provides evidence that waxy crude oil gels exhibit true yield stress and yielding process.

\section{ACKNOWLEDGEMENTS}

This work forms part of a continuing programme of work on the rheology of waxy crude oils which has been sponsored over the years by the Libyan Petroleum Institute (Libya), the support of whom we gratefully acknowledge. We also acknowledge BP and the National Oil Corporation (NOC) of Libya for providing the oil samples.

\section{$43 \quad 6 . \quad$ NOTATIONS}

$44 \quad a_{f} \quad$ Shear rate or fracture acceleration 


$\begin{array}{rll}1 & L & \text { Pipeline length } \\ 2 & R & \text { Pipeline radius } \\ 3 & R_{g} & \text { Gel front radius } \\ 4 & T & \text { Temperature } \\ 5 & T_{W A} & \text { Wax appearance temperature } \\ 6 & T_{W D} & \text { Wax disappearance temperature } \\ 7 & \Delta p & \text { Pressure drop in pipeline } \\ 8 & \dot{\gamma} & \text { Shear Rate } \\ 9 & t & \text { Time } \\ 10 & t_{f} & \text { Time for complete fragmentation } \\ 11 & \tau & \text { Shear stress } \\ 12 & \tau_{e} & \text { Elastic yield stress } \\ 13 & \tau_{s} & \text { Static yield stress } \\ 14 & \tau_{f} & \text { Fragmentation yield stress } \\ 15 & \tau_{d} & \text { Dynamic yield stress } \\ 16 & \tau_{r s t} & \text { Restart yield stress in pipeline }\end{array}$

17 6. REFERENCES

18 Andrade, D.E., da Cruz, A.C., Franco, A.T., Negrão, C.O., 2015. Influence of the initial cooling 19 temperature on the gelation and yield stress of waxy crude oils. Rheologica Acta 54 (2), 149-157.

20 Andrade, D.E., Moisés, A., Marcelino, N., Negrão, C.O., 2018. Non monotonic response of waxy oil gel 21 strength to cooling rate. Rheologica Acta 57 (10), 673-680.

22 Barnes, H.A., 1999. The yield stress - a review or ' $\pi \alpha \nu \tau \alpha \rho \varepsilon 1$ ' - everything flows?. J. Non-Newtonian Fluid 23 Mech. 81 (1), 133-178.

24 Barnes, H.A., 2007. The 'Yield stress myth?' paper-21 years on. Appl. Rheol. 17, 2007, 43110-43115.

26 Betancourt, S., Davies, T., Kennedy, R., Dong, C., Elshahawi, H., Mullins, O.C., Nighswander, J., O’Keefe, 27 M., 2007. Advancing fluid-property measurements. Schlumberger Oilfield Review 19 (3), 56-70.

28 Cawkwell, M. G., Charles, M. E. J., 1989. Characterization of canadian arctic thixotropic gelled oils 29 utilizing an eight parameter model. J. Pipelines 7, 251-256.

30 Chalaa, G.T., Sulaimanb, S.A., Japper-Jaafarb, A., 2018. Flow start-up and transportation of waxy crude 31 oil in pipelines-A review. J. Non-Newtonian Fluid Mech. 251, 69-87.

32 Chang, C., Boger, D.V., Nguyen, Q.D., 1998. The yielding of waxy crude oils. Ind. Eng. Chem. Res. 37 (4), 33 1551-1559. 
Chang, C., Nguyen, Q.D., Rønningsen, H.P., 1999. Isothermal start-up of pipeline transporting waxy crude oil. J. Non-Newtonian Fluid Mech. 87 (2), 127-154.

Chang, C., Boger, D.V., Nguyen, Q.D., 2000. Influence of thermal history on the waxy structure of statically cooled waxy crude oil. SPE J. 5 (2), 148-157.

Chen, J., Zhang, J., Li, H., 2004. Determining the wax content of crude oils by using differential scanning calorimetry. Thermochim. Acta 410, 23-26.

Chen, S., Øye, G., Sjoblom, J., 2006. Characterization and rheological properties of waxy oils. Annu Trans. Nord. Rheol. Soc. 14, 6-11.

Cheng, D. C-H., 1985. Yield stress: a time-dependent property and how to measure it, Report No. LR 540 (MH), Warren Spring Laboratory, Department of Industry, UK, August 1985.

Davidson, M.R., Nguyen, Q.D., Chang, C., Rønningsen, H.P., 2004. A model for restart of a pipeline with compressible gelled waxy crude oil. J. Non-Newtonian Fluid Mech. 123 (2), 269-280.

Dimitriou, C.J., McKinley, G.H., Venkatesan, R., 2011. Rheo-PIV analysis of the yielding and flow of model waxy crude oils. Energy \& Fuels 25 (7), 3040-3052.

Energy Information Administration (EIA), 2018. International Energy Outlook, 2018. EIA.doe.gov

Fakroun, A., 2018. PhD Thesis The Development of a Knowledge-Based Wax deposition, Three Yield Stresses Model and Failure Mechanisms for Re-starting Petroleum Field Pipelines. University of Bradford, UK.

Gibaud, T., Barentin, C., Taberleta, N., Mannevillea, S. , 2009. Shear-induced fragmentation of laponite suspensions. Soft Matter 5, 3026-3037.

Guo, X., Pethica, B.A., Huang, J.S., Adamson, D.H., Prud'homme, R.K., 2006. Effect of cooling rate on crystallization of model waxy oils with microcrystalline poly(ethylene butene). Energy Fuel 20, 250256.

Hou, L., Zhang, J., 2010. A study on creep behavior of gelled Daqing crude oil. Pet. Sci. Technol. 28, 690699.

Huang, Z., Lee, H.S., Senra, M., Fogler, H.S., 2011. A fundamental model of wax deposition in subsea oil pipelines. AIChE J. 57, 2955-2964.

Kane, M., Djabourov, M., Volle, J.L., 2004. Rheology and structure of waxy crude oils in quiescent and under shearing conditions. Fuel 83 (11), 1591-1605

Kok, M.V., Létoffé, J.M., Claudy, P., Martin, D., Garcin, M., Volle, J.L., 1996. Comparison of wax appearance temperatures of crude oils by differential scanning calorimetry, thermomicroscopy and viscometry. Fuel 75 (7), 787-790. 
Köka, M.F., Varfolomeevb, M.A., Nurgalievc, D.K., 2018. Wax appearance temperature (WAT) determinations of different origin crude oils by differential scanning calorimetry. J. of Petrol. Sci. Eng. $168,542-54$.

Lee, H.S., Singh, P., Thomason, W.H., Fogler, H.S., 2008. Waxy oil gel breaking mechanisms: adhesive versus cohesive failure. Energy Fuel 22, 480-487

Lin, M., Li, C.,Yang, F., Ma, Y., 2011. Isothermal structure development of Qinghai waxy crude oil after static and dynamic cooling. J. Petrol. Sci. Eng., 77 (3), 351-358.

Magda, J.J., El-Gendy, H., Oh, K., Deo, M.D., Montesi, A., Venkatesan, R., 2009. Time-dependent rheology of a model waxy crude oil with relevance to gelled pipeline restart. Energy Fuels 23, 1311-1315.

Marchesini, F.H., Alicke, A.A., de Souza Mendes, P.R., Ziglio, C.M., 2012. Rheological characterization of waxy crude oils: sample preparation. Energy Fuels 26, 2566-2577.

Møller, P.C., Mewis, J., Bonn, D., 2006. Yield stress and thixotropy: on the difficulty of measuring yield stresses in practice. Soft Matter 2 (4), 274-283.

Morozov, E.V., Falaleev, O.V., Martyanov, O.N., 2016. New insight into the wax precipitation process: in situ NMR imaging study in a cold finger cell. Energy Fuels 30, 9003-9013.

Mullin, J.W., 2001. Crystallization, 4th edn. Butterworth-Heinemann, Oxford, UK.

Oliveira, G.M., Cezar, O., Negrão, O.R., 2015. The effect of compressibility on flow start-up of waxy crude oils. J. of Non-Newtonian Fluid Mech. 220, 137-147.

Rønningsen, H. P., 1992. Rheological behaviour of gelled, waxy North Sea crude oils. J. Pet. Sci. Eng. 7, 177-213.

Rønningsen, H.P., 2012. Production of waxy oils on the norwegian continental shelf: experiences, challenges, and practices. Energy Fuels 26, 4124-4136.

Roy, U.S., Tirumkudulu, M.S., 2016. Universality in consolidation of colloidal gels. Soft Matter 12, 94029406.

Russell, R.J., Chapman, E.D., 1971. Pumping of 85.deg.F pour point Assam (Nahorkatiya) crude oil at 65.deg.F. J. Inst. of Pet. 57(554), 117-28.

da Silva, J.A.L., Coutinho, J.A., 2004. Dynamic rheological analysis of the gelation behaviour of waxy crude oils. Rheol. Acta 43 (5), 433-441.

Singh, P., Venkatesan, R., Fogler, H.S., Nagarajan, N.R., 2001. Morphological evolution of thick wax deposits during aging. AIChE J. 47(1), 6-18.

Speight, H.J.G., 2015. Handbook of Petroleum Product Analysis, 2nd Edition, John Wiley \& Sons, Inc. Hoboken, New Jersey, USA.

Southgate, J., 2004. PhD Thesis Wax removal using pipeline pigs. Durham theses, Durham University, UK. 
Tarcha, B.A., Forte, B.P., Soares, E.J., Thompson, R.L., 2015. Critical quantities on the yielding process of waxy crude oils. Rheologica Acta 54 (6), 479-499.

Van Der Geest, C., Guersoni, V.C.B., Merino-Garcia, D., Bannwart, A.C., 2015. A modified elastoviscoplastic thixotropic model for two commercial gelled waxy crude oils. Rheologica Acta 54 (6), 545561.

Van Der Geest, C., Guersoni, V.C.B., Merino-Garcia, D., Bannwart, A.C., 2017. Rheological study under simple shear of six gelled waxy crude oils, J. Non-Newtonian Fluid Mech. 247, 188-206.

Vassopoulos, D., Stiakakis, E., Kapnistos, M., 2007. Model Soft Colloids Out Of Equilibrium: Glass-like and Re-entrant Transitions. Rheology Reviews, 179-252.

Venkatesan, R., Nagarajan, N.R., Paso, K., Yi, Y.B., Sastry, A.M., Fogler, H.S., 2005. The strength of paraffin gels formed under static and flow conditions. Chem. Eng. Sci. 60 (13), 3587-3598.

Vinay, G., Wachs, A., Agassant, J.-F., 2006. Numerical simulation of weakly compressible Bingham flows: the restart of pipeline flows of waxy crude oils. J. Non-Newton. Fluid Mech. 136, 93-105.

Visintin, R.F.G., Lapasin, R., Vignati, E., D'Antona, P., Lockhart, T.P., 2005. Rheological behavior and structural interpretation of waxy crude oil gels. Langmuir 21 (14), 6240-6249.

Visintin, R.F.G., Lockhart, T.P., Lapasin, R., D'Antona, P., 2008. Structure of waxy crude oil emulsion gels. J. Non-Newtonian Fluid Mech. 149, 34-39.

Wardhaugh, L.T., Boger, D.V., 1991. The measurement and description of the yielding behavior of waxy crude oil. J. Rheol. 35 (6), 1121-1156.

Wardhaugh, L.T., Boger, D.V., 1991. Flow characteristics of waxy crude oils: application to pipeline design. AIChE J. 37 (6), 871-885.

Webber, R.M., 2001. Yield properties of wax crystal structures formed in lubricant mineral oils. Ind. Eng. Chem. Res. 40, 195-203.

World Energy Council, 2016. World Energy Resources.

Yi, S., Zhang, J., 2011. Relationship between Waxy Crude Oil Composition and Change in the Morphology and Structure of Wax Crystals Induced by Pour-Point-Depressant Beneficiation. Energy Fuels 25 (4), 1686-1696. 